\title{
Combination of FTIR Spectroscopy and Chemometric Method on Quantitative Approach - A Review
}

\author{
Verma K ${ }^{1}$, Akhtar MJ $^{2}$ and Anchliya $A^{1 *}$ \\ ${ }^{1}$ Department of Pharmaceutical Analysis, Indo-Soviet \\ Friendship College of Pharmacy, India \\ ${ }^{2}$ Department of Pharmaceutical Chemistry, Indo-Soviet \\ Friendship College of Pharmacy, India \\ *Corresponding author: Anchliya A, Department of \\ Pharmaceutical Analysis, Indo-Soviet Friendship College \\ of Pharmacy, Ferozepur GT. Road, Moga-142001, Punjab, \\ India
}

Received: August 07, 2020; Accepted: February 24, 2021; Published: March 03, 2021

\begin{abstract}
Fourier transform infrared spectroscopy is an effectual and noncritical approach for quantitative study of different types analytes present in pharmaceutical and foodstuffs. The present review describes the basic principles and the instrumentation of FTIR spectroscopy along with its sample preparation techniques, sample handling techniques and advancements. FTIR spectroscopy in combination with chemometrics techniques has been followed over long times. The main objective of this review is to assemble the data linked to application of FTIR spectroscopic and chemometrics techniques for the quantitative study of varieties of analytes like API, adulterants, caffeine, cocaine, lipids, fats \& oils, sugar and others. The FTIR spectroscopy with chemometrics techniques proved to be a beneficial methodology for quantitative study to routine analysis of these analytes.
\end{abstract}

Keywords: Quantification; FTIR spectroscopy; Applications; Chemometrics

\section{Introduction}

Infrared spectroscopy has been proposed as a potent device and also consider as a green technique for analysis $[1,2]$ because it only reagent requires is potassium bromide, promoting benefit as cost-efficient, low production of lethal waste product, less time require for analysis, no utilization of organic solvents and also provide opportunity for the analysis of material which is insoluble in commonly utilized solvents [3]. Fourier Transform Infrared Spectroscopy (FTIR) is an advanced approach for the analysis and detection of chemical compounds (i.e. organic and inorganic) according to their functional group [5]. It presents a significant knowledge of molecular structure [5], chemical composition, physical condition [6], energy state and chemical bonds of an analyte, when it absorbs infrared radiation, with the help of the IR spectrum [7].

A spectrum of IR can be split into 3 major regions: the first one is far-infrared (below $400 \mathrm{~cm}^{-1}$ ), second is Mid-Infrared (MIR) in range of 4000 to $400 \mathrm{~cm}^{-1}$, and the last is Near-Infrared (NIR) in the range of 13,000 to $4000 \mathrm{~cm}^{-1}$. MIR region is mainly utilized for numerous applications by employing IR spectroscopy, however, NIR and farinfrared regions were too offer significant data concerning materials [8]. In MIR spectroscopy, absorption of photons takes place and molecular vibrations get excited in the spectral regime of 2-20 $\mu \mathrm{m}$ which results in achieving an unambiguous absorption pattern that may aid as molecular fingerprints for the detection and quantification of analytes [9]. Chemical and biochemical reactions can be identified by this technique from IR spectrum on the basis of appearance or disappearance of specific band of functional group or by observing the shift in band if structure involve change in structure of end product [10]. FTIR spectrometer is high demand in laboratories for its rapid functioning, better signal to noise ratio [11] non-destructive and easy tools for analysis, with least sample preparation is required $[12,13]$. In quality control laboratories, this technique can be utilized for qualitative along with quantitative determination [14]. As the intensities of the absorption band in the spectrum are directly proportional to concentration i.e. it obeys Beer's law and when coupled with chemometric techniques, FTIR spectroscopy serves as a means for quantitative study [12]. As per this law, the area under the absorption band or intensity of signal provides information regarding the concentration of an analyte [15] and calibration curve against band intensity and concentration can be constructed from standard analyte and this help us to know the concentration of an analyte under examination present in the sample [16].

Photon transfer into molecule occurs when it absorbs IR radiation and get excites jump to higher energy state which results in vibration of bond in molecules, they are:- 1) Stretching Vibration: symmetric \& asymmetric and 2) Bending Vibration: scissoring, twisting, rocking \& wagging, arising at different wavenumber/frequencies of light spectrum in infrared region [17]. The amount of light absorbed by sample in different frequencies relates to vibrational frequencies of bonds present in the test sample. Alteration in dipole moment between functional is a necessary criteria for the molecules to be IR active [18]. It add a plus point of real-time process and maintenance requirements is quite low, a contrast to gas chromatography, and also cost-efficient and provide detailed or specific information regarding structure as compared with mass spectroscopy [19]. The wavenumber range between $4000-1500 \mathrm{~cm}^{-1}$ and $1500-500 \mathrm{~cm}^{-1}$ are signified as functional group region and fingerprint region, respectively [20]. Absorption band in the functional group region typically arises from molecular vibrations of fundamental transitions and produces a highly characteristic pattern of absorption band. It operates at a very low energy light wave so damage in a sample due to ionization is not a concern [21]. Based on literature survey, we reviewed the research on application of FTIR spectroscopic and chemometrics techniques for the quantitative study of varieties of analytes like API, adulterants, caffeine, cocaine, lipids, fats \& oils, sugar and others. 


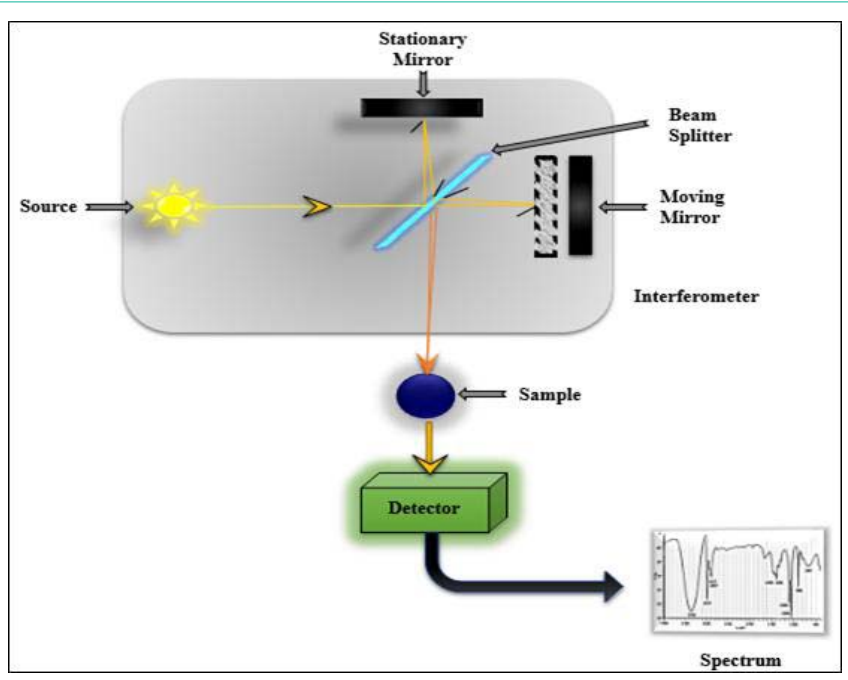

Figure 1: Instrumentation of FTIR.

\section{Instrumentation}

FTIR instrumentation is quite simple except when the source employed is the synchrotron, and produce highly accurate and precise data having high spatial resolutions [22]. For the IR region, the light source is like tungsten filament which is heated and radiates polychromatic light. Then the light beam is focused on the Michelson interferometer, containing a beam splitter to slight light source into two i.e. $50 \%$ transmits and 50\% reflects. Further these both split beams. The split beams stick two different mirrors, the first one is motionless and the other continuously oscillate backward and forward direction with definite frequency and amplitude. After that, these two beams merge again at a beam splitter and interfere due to the difference in optical path length then move towards sample [23] (Figure 1). Wavelength of emitted light is measured by interferometer through interference patterns, aid to enhance accuracy. Total scans can increased as per the quality required for analysing the sample [24]. The $x$ and $y$-axis of the spectrum signifies the wavenumber and absorbance or transmittance respectively [25].

Sample preparation methods: To read the FTIR spectrum, it's essential to recognise what kinds of sample holders or cells are

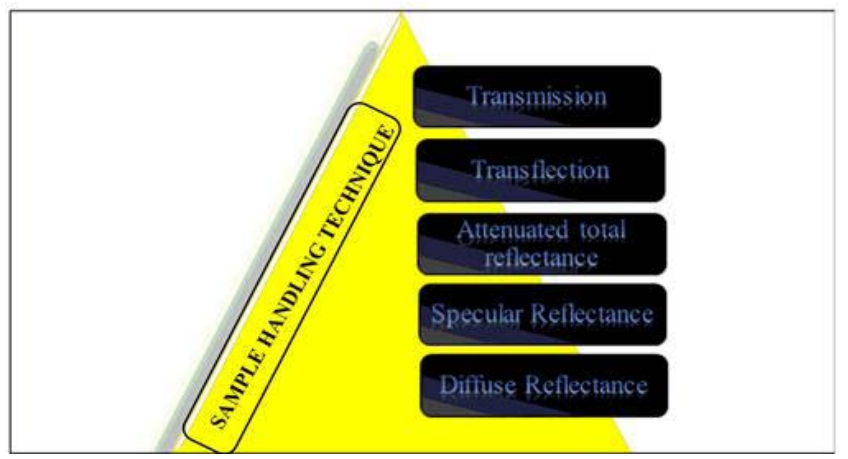

Figure 2: Various Sampling Handling Technique.

being used during analysis [26]. Also, the sample type and sample preparation method should also be known. Firstly, the sample phase can be of any type i.e. solid, liquid or gas [27]. Three types of sample preparation methods (Table 1 ).

Sample handling technique: Depict various sample handling techniques (Figure $2 \&$ Table 2).

\section{Instrument Development in FTIR Spectroscopic}

Advancements in FTIR spectroscopy (Figure 3).

\section{IR-MALDESI}

Infrared matrix assessed laser desorption electrospray ionization technique has been industrialised recently. It is proficient to provide great spatial resolute Mass Spectrometry Imaging (MSI) at about $50 \mu \mathrm{m}$ resolution. This provides an easy understanding of molecular distribution present in complex tissues like biomarkers, peptide, proteins etc. of the biological system. The Instrument includes an adaptable iris, a beam expander, and a spherical focusing lens for reducing tissue ablation diameters during MSI. The potential of the newly built optical system was shown using ovarian tissue of hen revealing detailed features of tissue at $50 \mu \mathrm{m}$ resolution [28].

\section{Thermal IR Imaging Spectrometer (TIS)}

A TIS technique operating in the 7-13 $\mu \mathrm{m}$ spectral region of IR was developed by the Mars Orbiting Mission team. This developed

Table 1: Types of Sample Preparation Method.

\begin{tabular}{|c|c|c|c|c|c|}
\hline Sample & Preparation of Sample & Advantage & Disadvantage & Remark & Reference \\
\hline Liquid & $\begin{array}{l}\text { Between two polished } \mathrm{NaCl} \text { or } \mathrm{KBr} \text {, a } \\
\text { drop of liquid sample was placed }\end{array}$ & No solvent is required & $\begin{array}{l}\text { Breaking of salt plates and } \\
\text { get easily soluble in } \mathrm{H}_{2} \mathrm{O}\end{array}$ & Sample should be free from water & [26] \\
\hline \multirow{3}{*}{ Solid } & $\begin{array}{l}\text { 1) } \mathrm{KBr} \text { pellet is a blend of organic } \\
\text { compound and } \mathrm{KBr} \text { is pressed to form a } \\
\text { transparent pellet or window. }\end{array}$ & $\begin{array}{l}\mathrm{KBr} \text { is transparent in the IR } \\
\text { range }\end{array}$ & $\mathrm{KBr}$ absorbs water & $\begin{array}{l}\text { Dried place was necessary to } \\
\text { store } \mathrm{KBr} \text { as it may gain moisture } \\
\text { from surrounding }\end{array}$ & [77] \\
\hline & $\begin{array}{l}\text { 2) By grinding organic solid and Nujol } \\
\text { a mineral oil, Nujol mull is prepared } \\
\text { employing mortar and pestle for some } \\
\text { time and placed it in between two salt } \\
\text { plate }\end{array}$ & $\begin{array}{l}\text { A simple and fast method } \\
\text { and also special equipment } \\
\text { was not necessary. }\end{array}$ & $\begin{array}{l}\text { Nujol absorbs in the IR } \\
\text { region of } 2920-2850,1460 \text {, } \\
\text { and } 1380 \mathrm{~cm}^{-1}\end{array}$ & $\begin{array}{l}\text { For qualitative analysis only and } \\
\text { not for quantitative analysis. }\end{array}$ & - \\
\hline & $\begin{array}{l}\text { 3) Thin solid films of organic compounds } \\
\text { are made by placing the solution having } \\
\text { compound on a salt plate. }\end{array}$ & $\begin{array}{l}\text { Spectra are free from } \\
\text { interfering absorbance } \\
\text { bands because sample was } \\
\text { prepared undiluted }\end{array}$ & & The solvent should be evaporated. & - \\
\hline Gas & $\begin{array}{l}\text { Longer cell having salt-coated window } \\
\text { was used to place the gas sample. }\end{array}$ & $\begin{array}{l}\text { Several reflections can } \\
\text { be employed to produce } \\
\text { the effective path length } \\
\text { providing } 40 \mathrm{~cm}\end{array}$ & Sensitivity is not sufficient & $\begin{array}{l}\text { Long-path-length about more } \\
\text { than } 10 \mathrm{~cm} \text { cells are employed } \\
\text { to examine dilute or the sample } \\
\text { which are weakly absorbing }\end{array}$ & 27] \\
\hline
\end{tabular}


Table 2: Various Sampling Handling Technique.

\begin{tabular}{|l|l|l|}
\hline \multicolumn{1}{|c|}{ Technique } & \multicolumn{1}{|c|}{ Comments } & \multicolumn{1}{c|}{ Types of Sample to be Analyzed } \\
\hline Transmission & $\begin{array}{l}\text { Based on the transmission of infrared radiation from } \\
\text { the sample and then the substrate ahead producing } \\
\text { radiation is detected. }\end{array}$ & $\begin{array}{l}\text { Pellet containing organic powers or mull form, thin polymer layers, } \\
\text { soluble polymers, regular or irregular-form polymers, thermoplastic } \\
\text { powders, dark polymer films, runny or viscid liquids, and gases. }\end{array}$ \\
\hline Transflection & $\begin{array}{l}\text { After transmitting the absorbed infrared radiation by } \\
\text { the sample, reflected to substrate and then transmit } \\
\text { again to the sample is detected }\end{array}$ & $\begin{array}{l}\text { Biofluids, quantification of several serum components concerns to } \\
\text { clinical assays and dry films }\end{array}$ \\
\hline ATR & $\begin{array}{l}\text { Principles of functioning based on total internal } \\
\text { reflection }\end{array}$ & $\begin{array}{l}\text { Laminates, paints, rubbers, plastics, coating, crushable solids, runny } \\
\text { or viscid liquids, biological stuff, and natural powder }\end{array}$ \\
\hline Specular Reflectance & $\begin{array}{l}\text { The incident radiation concentrated to sample may } \\
\text { directly be reflected by the surface of the sample and } \\
\text { produce a specular reflection. }\end{array}$ & $\begin{array}{l}\text { Metallic surfaces, coated materials on metals, thin layers on } \\
\text { reflective substrates, and silicon wafers } \\
\text { [78] }\end{array}$ \\
\hline Diffuse Reflectance & $\begin{array}{l}\text { Reflected electromagnetic radiation accumulates in } \\
\text { roughened surfaces and then analyzed. }\end{array}$ & $\begin{array}{l}\text { Soft powders, tablets, powder mixtures, hard and inflexible polymers, } \\
\text { paint and varnish surfaces }\end{array}$ \\
\hline $\begin{array}{l}\text { Photoacoustic } \\
\text { Spectroscopy (PAS) }\end{array}$ & $\begin{array}{l}\text { It is based on the absorption of electromagnetic } \\
\text { radiation by molecule to be analyzed and then } \\
\text { transform optical event to an acoustic }\end{array}$ & $\begin{array}{l}\text { Powders, viscous glues, polymer pellets, single fibres and single } \\
\text { crystals }\end{array}$ \\
\hline [8]
\end{tabular}

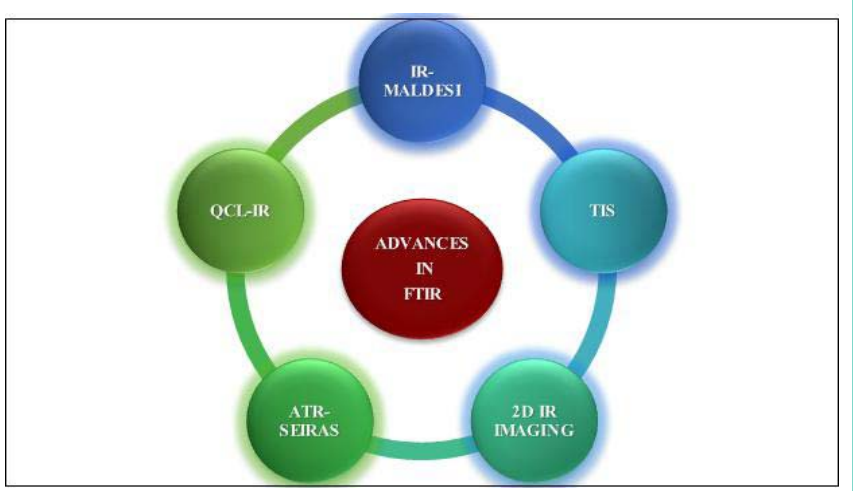

Figure 3: Advancements in FTIR Spectroscopy.

was employed to identify the thermal IR radiation emitted from the Martian milieu, to make it possible to estimate the Mars surface temperature and mapping its surface composition. This instrument having miniaturized components is lightweight $(3.2 \mathrm{~kg})$ and needs only $6 \mathrm{~W}$ of power requirement [29].

\section{2-Dimensional IR imaging}

For measuring a 2D IR imaging system, a microscope having a wide-field that has the latest focal plane array detector and midIR pulse shaping was reported. It produces hyper spectral picture around 16,000 2D IR spectra with several frequency dimensions and diffraction-limited spatial resolution. The ability of this method was confirmed by imaging blend of metal carbonyl absorbed polystyrene beads [30].

\section{Attenuated Total Reflection Surface-Enhanced IR Spectroscopy (ATR-SEIRAS)}

A new technique has been developed by coupling synchrotron as a source for IR in ATR-SEIRAS. It has higher sensitivity and allows the spectral detection of adsorbed molecules even of femtomole quantities. This was proved by spectral measurement of 4 Methoxyridine (MOP) which was adsorbed as a monolayer on the surface enhancing electrode of gold film under completely functioning electrochemical circumstances. Enhancement in noise by a factor of 15 was attained by utilizing tiny apertures with synchrotron infrared source in comparison to a thermal infrared source. Due to the minimized noise intensities, a good IR spectra of molecules up to 2.5 femto-moles confined to $125 \mu \mathrm{m}^{2}$ beam spot [31].

\section{Quantum Cascade Laser IR (QCL-IR)}

QCL-IR is a novel tactic developed to analyze airborne concentrations in Respirable Crystalline Silica (RCS). Sampling means developed for QCL based infrared spectroscopy consists of usual aerosol filter collection, focused spot sample collection from the aerosol phase and dried spot collection from the deposition of liquid suspensions. IR spectrum obtained in $750-1030 \mathrm{~cm}^{-1}$ range from this instrument were compared with standard FTIR and results showed QCL-IR provided significant lower detection limits for RCS (=330ng) in comparison to the standard FTIR [32].

\section{Application}

\section{Quantitative analysis of pharmaceuticals}

Application to amoxicillin: A lot of effort has been done for the development of a method that can be used as an analytical tool for the determination of amoxicillin in various matrices. Yet the current methods require toxic solvents which are harmful to the operators and also for the environment like in HPLC, UPLC or iodometry. Though some green analytical methods have also been stated in the literature but no one is focused on quantification of amoxicillin in capsules. Stefany Fanelli et al., validated an analytical method in accordance with ICH and Brazilian legislation for amoxicillin analysis in a capsule that was environmentally friendly utilizing IR spectrophotometry in the mid-infrared region i.e. $1815-1736 \mathrm{~cm}^{-1}$. Method validation was performed in the concentration range of 0.5 $1.5 \mathrm{mg} /$ pellet. The $\mathrm{R}^{2}$ value was 0.9971 and accuracy was proved using a recovery study with an average recovery of $100.42 \%$. \%RD for the six concentrations on the same day and under the same experimental condition was $3.80 \%$. The amoxicillin content in capsule found was $100.34 \%$, which was in the range satisfying Brazilian pharmacopeia (90-120\%). So this method satisfied all the parameters of ICH and Brazilian legislation and can be used in labs for its analysis as it is a low cost and green approach [33] (Table 3).

Quantitative analysis of curcuminoid in tablet dosage form: In curcuminoid, mainly curcumin and desmethoxycurcumin have biological activities such as antioxidant, anti-inflammatory, and anticancer. To analyze these compound chromatographic and but this method requires more time and labours, so, as to ease the analysis of these compounds, Chairany Siregar et al., report a FTIR spectroscopy with multivariate calibration method to quantify curcumin and desmethoxycurcumin at definite first derivative IR 
Table 3: Quantitative Analysis of Pharmaceuticals.

\begin{tabular}{|c|c|c|c|c|c|c|c|c|}
\hline Sr. No. & Drug & Wavenumber $\left(\mathrm{cm}^{-1}\right)$ & R2 & $\%$ RSD & LOD (mg) & LOQ (mg) & $\begin{array}{l}\text { Marketed formulation } \\
\text { (\%) }\end{array}$ & Reference \\
\hline 1 & Amoxicillin & $1815-1736$ & 0.9971 & 3.8 & - & - & 100.34 & 37 \\
\hline 2 & $\begin{array}{c}\text { Curcuminoid and } \\
\text { desmethoxycurcumin }\end{array}$ & $\begin{array}{c}2975-660 \mathrm{~cm}^{-1} \\
1784-1587 \mathrm{~cm}^{-1}\end{array}$ & $\begin{array}{c}0.9968 \& \\
0.9964 \\
\text { and } \\
0.9954 \& \text { \& } \\
0.9916\end{array}$ & - & - & - & - & [38] \\
\hline 3 & Cilnidipine & 1697 & $\begin{array}{c}0.9994 \& \\
0.9999\end{array}$ & Less than 2 & $0.22-0.050$ & $0.60-0.17$ & $9.986 \mu \mathrm{g} / \mathrm{mg}$ & 39 \\
\hline \multirow{8}{*}{4} & \multirow{8}{*}{ Paracetamol } & \multirow{8}{*}{$1800-1000$} & \multirow{8}{*}{0.999} & \multirow{8}{*}{ - } & \multirow{8}{*}{0.005} & \multirow{8}{*}{0.018} & $227.18 \mathrm{mg} / \mathrm{tablet}$ & \multirow{8}{*}{40} \\
\hline & & & & & & & $229.05 \mathrm{mg} /$ tablet & \\
\hline & & & & & & & $226.43 \mathrm{mg} / \mathrm{tablet}$ & \\
\hline & & & & & & & $223.82 \mathrm{mg} /$ tablet & \\
\hline & & & & & & & $226.06 \mathrm{mg} / \mathrm{tablet}$ & \\
\hline & & & & & & & $225.86 \mathrm{mg} / \mathrm{tablet}$ & \\
\hline & & & & & & & $228.45 \mathrm{mg} / \mathrm{tablet}$ & \\
\hline & & & & & & & $227.57 \mathrm{mg} /$ tablet & \\
\hline 5 & Norfloxacin & $1770-1649.138$ & 0.9936 & 3.16 & $0.18 \mathrm{mg} /$ pellet & $0.55 \mathrm{mg} / \mathrm{pellet}$ & $98 \%$ & 41] \\
\hline
\end{tabular}

spectral range of 2975-660 $\mathrm{cm}^{-1}$ via Partial Least Square Regression (PLSR) for curcumin while for desmethoxycurcumin spectra was taken in between $1784-1587 \mathrm{~cm}^{-1}$ via FTIR normal spectra. $\mathrm{R}^{2}$ was found to be less than 0.99 for calibration and validation models to quantify curcumin and desmethoxycurcumin via Partial Least Square regression, with RMSEC and RMSEP values of $0.126 \%$ and $0.254 \%$ for curcumin while $0.000427 \%$ and $0.000754 \%$ for desmethoxycurcumin, respectively.Accuracy and precision of the method were found to be appropriate. Hence, they concluded that for routine analysis, the developed method was suitable and rapid [34] (Table 3).

Cilnidipine in tablet dosage form: Ashish Patel et al., established and validated an approach for the determination of Cilnidipine using FTIR present in a single dosage formulation which was a novel, fast, accurate, easy, economical, less time requiring and environmentally friendly method. He took carbonyl group peak at peak $1697 \mathrm{~cm}^{-1}$ as a measure for absorbance for the method. $\mathrm{R}^{2}$ was found to be 0.9994 and 0.9999 with respect to absorbance and peak area, respectively. $\%$ RSD was not more than $2 \%$. Recovery values were found to be in the range of 99.8-102.5 and 99.8-101.4 with respect to absorbance and peak area respectively. This method was then used for the assay of marketed formulation by taking $10 \mu \mathrm{g} / \mathrm{mg}$ of drug and found to be $9.986 \mu \mathrm{g} / \mathrm{mg}$. the method was validated for analysis of Cilnidipine in tablets and was obtained to be less time utilizing than other methods [35] (Table 3).

Direct quantification of paracetamol content in solid pharmaceutical formulations: Various types of methods utilizing different techniques have been used for the quantification of paracetamol like titrimetry, UV-visible spectrophotometry, spectrofluorimetry, flow injection spectrophotometry, HPLC, GCMS, etc. But these methods cannot be used for routine analysis as they are high time consuming, require a higher amount of solvents, high cost for analysis, some including tedious sample preparation methods. Thus, there was a demand for a method that is sensitive, rapid, cost-effective, and a green method. Muhammad Ali Mallah developed a method for fulfilling these requirements. He established

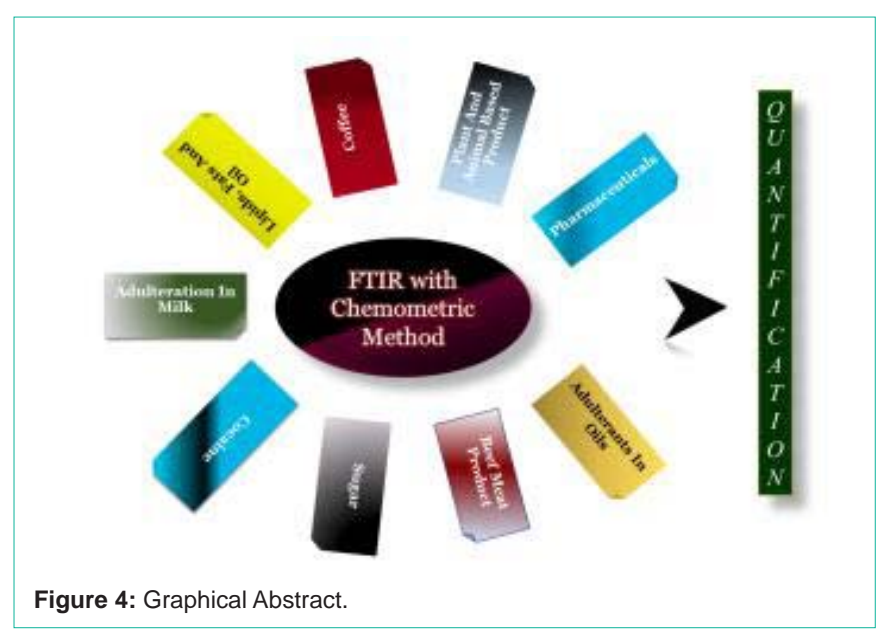

a approach for the determination of Paracetamol present in solid dosage formulations using transmission FTIR spectroscopy. Two chemometric models were used first- simple beer's law and secondpartial least square in the spectral range of $1800-1000 \mathrm{~cm}^{-1}$. R', LOD, and LOQ were found to be $0.999,0.005 \mathrm{mg} \mathrm{g}^{-1}$ and $0.018 \mathrm{mg} \mathrm{g}^{-1}$ respectively. Paracetamol content in eight different samples of $225 \mathrm{mg} /$ tablet was found to be 227.18, 229.05, 226.43, 223.82, 226.06, 225.86, 228.45 , and $227.57 \mathrm{mg} /$ tablet, respectively. Through interference study on tablet dosage form, they examine the influence of excipient and no interference was observed. They concluded that the method is a green analytical method as it does not involve unsafe solvents or larger run times or pre-sample preparation [36] (Table 3).

Norfloxacin in raw material: Many analytical methods have been described in the literature for norfloxacin analysis which is complex and requires a large volume of organic solvent. A latest method for norfloxacin analysis in raw material was established by Jessica Sayuri Hisano Natori et al., using FTIR spectroscopy which did not require organic solvents and was a green method. In their method, they took 1770 to $1649.138 \mathrm{~cm}^{-1}$ spectral region for the quantification. The $\mathrm{R}^{2}$ 
Table 4: Quantitative Analysis for Adulterants in Oils.

\begin{tabular}{|c|c|c|c|c|c|c|c|}
\hline Sr. No. & Matrix & Analyte & Wavenumber $\left(\mathrm{cm}^{-1}\right)$ & R2 & RMSE & $\begin{array}{l}\text { Content of } \\
\text { analyte }\end{array}$ & Reference \\
\hline 1 & Peanut Oil & Extra Virgin Olive Oil & $600-1800 \& 2750-3050$ & $0.960 \& 0.977$ & RMSEP: 1.49 and $1.05 \%$ & $0.5 \% \mathrm{~V} / \mathrm{V}$ & {$[42]$} \\
\hline 2 & Patchouli Oil & Castor Oil, \& Palm Oil & $\begin{array}{c}1200-1000,3100-2900 \& \\
1200-1000\end{array}$ & $\begin{array}{l}0.9974 \& 0.9984 \\
0.9816 \& 0.9974\end{array}$ & $\begin{array}{c}\text { RMSEP: } 2.57 \% \& 1.79 \% \\
6.89 \& 2.57 \%\end{array}$ & - & [43] \\
\hline 3 & Olive Oil & Edible Vegetable Oils & $\begin{array}{l}3100-2700 \\
1800-1600 \\
1205-1080\end{array}$ & 0.86 & $\begin{array}{l}\text { RMSEV: } 17.6 \\
\text { MAEV: } 14.6 \\
\text { MdAEV: } 16.0\end{array}$ & - & [44] \\
\hline 4 & Edible Oils & Used Frying Oils & $1550-650$ & 0.9822 & - & more than $1 \%$ & [45] \\
\hline 5 & $\begin{array}{c}\text { Cold-Pressed Wheat } \\
\text { Germ Oil }\end{array}$ & $\begin{array}{l}\text { Sunflower Oils \& } \\
\text { Soybean Oils }\end{array}$ & $4000-650$ & $>0.9990 \&>0.9968$ & $\begin{array}{c}\text { RMSEC: } 0.56-1.98 \% \& \\
0.68-4.46 \% \\
\text { RMSECV: } 0.99-1.77 \% \text { \& } \\
1.09-5.12 \%\end{array}$ & $\begin{array}{c}<0.56 \% \& \\
<0.99 \%\end{array}$ & {$[46]$} \\
\hline
\end{tabular}

value was 0.9936 . For repeatability, \%RSD was found to be 3.16 . The recovery value was 99.42 with \%RSD 2.19. LOD and LOQ were 0.18 $\mathrm{mg} /$ pellet and $0.55 \mathrm{mg} /$ pellet. The assay result performed for NOR RS showed a mean content of $98 \%$. The method was thus validated and can be used for routine analysis [37] (Table 3).

\section{Quantitative analysis for adulterants in oils}

Adulteration of extra virgin olive oil with peanut oil: Edible oils were readily adulterated with low cost oils, degraded oils, and toxic mineral oils by the manufacturer to increase profit but it affects severe public health. So, Magda Vasconcelos et al., develop a procedure to predict the level of peanut oil adulterants in extra virgin olive oil by FTIR-ATR spectroscopy merged with principal component analysis and PLS-R techniques. They select two sets of frequency ranges, set $\mathrm{A}$ 600 to $1,800 \mathrm{~cm}^{-1}$ and 2,750 to $3,050 \mathrm{~cm}^{-1}$ and set $B$ included 17 discrete absorbance peaks examined using PCA. On the basis of obtained data from the FTIR spectra two calibration models (i.e. PCR and PLS-R), for the prediction of olive oil adulteration, was prepared and $\mathrm{R}^{2} 0.960$ and 0.977 and root mean square error prediction, 1.49 and $1.05 \%$ was found, respectively. LDA (linear discriminant analysis) was utilized to check the presence or absence of adulteration of PEO in EVOO and the lowest measurable concentration of $\mathrm{PEO}$ was found less than $5 \% \mathrm{v} / \mathrm{v}$. From the result, they concluded that FTIR with PLS-R is a reliable method to quantify and differentiate PEO in EVOO by using wavenumbers $3,007,2,922,2,853,1,754,1,160$, and $1,117 \mathrm{~cm}^{-1}$. Future perspective from this research would be with the aim to reduce the number of wavenumbers required to differentiate edible oils [38]. The results have been depicted in (Table 4).

Patchouli oil adulteration: For economical profit, expensive oils such as patchouli oil readily adulterated with cheaper oils. Zaki Fahmi et al., develop a methodology for the quantification of Patchouli Oil $(\mathrm{PaO})$ adulterated with a combination of Castor Oil (CO) and Palm Oil (PO), utilizing FTIR spectroscopy together with multivariate calibration method (i.e. Partial Least Square regression). They take normal spectral and select wavenumber from 1200-1000 and 3100$2900 \mathrm{~cm}^{-1}$ for the quantification of $\mathrm{PaO}$ in $\mathrm{PO}$ with $\mathrm{R}^{2}$ and RMSEP of 0.9974 and $2.57 \%$, respectively for calibration model whereas for validation model $\mathrm{R}^{2}$ and RMSEP was found to be 0.9984 and $1.79 \%$, respectively. Also, normal spectra of wavenumber range from 1200$1000 \mathrm{~cm}^{-1}$ were selected for the quantification $\mathrm{PaO}$ in $\mathrm{CO}$ with $\mathrm{R}^{2}$ and RMSEP of 0.9816 and $6.89 \%$ (for calibration) and 0.9974 and $2.57 \%$ (for validation), respectively. They also perform Discriminant analysis to classify $\mathrm{PaO}$ and $\mathrm{PaO}$ admixed with $\mathrm{PO}$ and $\mathrm{CO}$ and no misclassification were observed. From the result, they concluded that this method provides a suitable model to study adulteration of $\mathrm{PaO}$ with PO and CO [39] (Table 4).

Olive oil in blends with any edible vegetable oils: During quality control in laboratories a mixture in olive oils with other seed oils, if any, was not able to detect that which or how many seed oils were exercised for adulteration. For this motive, Jiménez-Carvelo et al., established a approach for discrimination, detection, and quantification of olive oil in blends with several other edible oils. Wavenumber range from $3100-2700 \mathrm{~cm}^{-1}, 1800-1600 \mathrm{~cm}^{-1}$ and 1205 $1080 \mathrm{~cm}^{-1}$ were preferred form FTIR spectra. The classification model to identify the adulterants in olive oils with vegetables edible oils were constructed for the inspection of the classification method before moving for quantification. After that PLS-R model was constructed for the quantitative prediction. $\mathrm{R}^{2}$, RMSEV, Mean Absolute Error of Validation (MAEV) and Median Absolute Error of Validation (MdAEV) were found to be $0.86,17.6,14.6$ and 16.0 respectively. They successfully quantify the extent of olive oil in vegetable oils employing the PLS-R model [40] (Table 4).

Edible oils adulterated with used frying oils: There is a need to establish a rapid detection of adulteration in edible oils as adulteration with cheaper oils becomes a great concern nowadays. Yuxing Kou et al., presented a validation method by FTIR spectroscopy for the detection of frying oils as an adulterant in edible oil. They select spectral ranges $1550-650 \mathrm{~cm}^{-1}$ using the PLS method to construct a model for quantitative analysis. Linear correlations (with $\mathrm{R}^{2}=0.9822$ ) were observed when they plot a graph between the concentration of actual and predicted values. Hence they concluded that this method is a beneficial tool means for the detection of adulteration in edible oil [41]. The results have been depicted in (Table 4).

Cold-pressed wheat germ oil adulteration: Cold-pressed oils are expensive and hence readily adulterated with cheaper or low-quality vegetable oils. Fatma Nur Arslan et al., describes a rapid method to recognise the of adulteration in cold-pressed Wheat Germ Oil (WGO) adulteration with Sunflower Oils (SFO) and Soybean Oils (SBO) by using ATR-FTIR spectroscopy with PLSR multivariate data analysis. They select a spectral region from $4000-650 \mathrm{~cm}^{-1}$. Soft independent modelling of class analogies analysis employed to classify edible oils and results in $100 \%$ classification of edible oils. They construct a PLSR model with a correlation coefficient of $>0.9990$ and $>0.9968$ for WGO-SFO and WGO-SBO, respectively. Content of SFO and SBO was quantified to be $<0.56 \%$ and $<0.99 \%$, respectively, as adulterants in unidentified mixture by using PLSR. RMSEC and RMSECV for the mixtures of WGO-SFO and WGO-SBO was found to be $0.56-1.98 \%$ 


\begin{tabular}{|c|c|c|c|c|c|c|c|c|}
\hline $\begin{array}{l}\text { Sr. } \\
\text { No. }\end{array}$ & Matrix & Analyte & $\begin{array}{l}\text { Wavenumber } \\
\left(\mathrm{cm}^{-1}\right)\end{array}$ & R2 & RSD & $\begin{array}{l}\text { LOD/LOQ } \\
(\%)\end{array}$ & Errors & Reference \\
\hline 1 & Goat Milk & Cow Milk & $4000-450$ & 0.991 & 4.4624 & 4.202 (LOD) & $\begin{array}{l}\text { RMSEP:1.40078 } \\
\text { REP: } 0.0078 \% \\
\text { SEP: } 1.5906\end{array}$ & [47] \\
\hline 2 & Camel Milk & Cow Milk & $3000-920$ & 0.9939 & - & 2.595 (LOD) & $\begin{array}{l}\text { RMSEP: } 0.665 \\
\text { SEP: } 0.940 \\
\text { Relative Error: } 3.8 \%\end{array}$ & [48] \\
\hline 3 & Cow Milk & Formalin & $\begin{array}{c}700-2500 \mathrm{~nm} \\
(\mathrm{NIR})\end{array}$ & 0.9696 & - & $\begin{array}{c}\text { Less than } 2 \\
\text { (LOQ) }\end{array}$ & $\begin{array}{l}\text { RMSE:0.086 } \\
\text { RMSECV:1.38 } \\
\text { RMSEP:1.05 }\end{array}$ & [49] \\
\hline 4 & Milk & Melamine & $4000-5880$ (NIR) & 0.97 & - & - & SEP: 0.015 & [50] \\
\hline 5 & Cow Milk & $\begin{array}{c}\text { Tetracycline, } \\
\text { Chlortetracycline } \\
\& \\
\text { Oxytetracycline }\end{array}$ & $4000-550$ & $\begin{array}{c}0.997 \text { to } 0.999 \\
\text { (calibration) \& } \\
0.989-0.999 \text { (validation) }\end{array}$ & - & $>10 \mu \mathrm{g} / \mathrm{l}(\mathrm{LOD})$ & $\begin{array}{c}\text { Standard error of calibration: 1.81-2.95 } \\
\text { (calibration) \& } \\
1.21-2.93 \text { (validation) }\end{array}$ & [51] \\
\hline
\end{tabular}

and $0.68-4.46 \%$ and $0.99-1.77 \%$ and $1.09-5.12 \%$, respectively. Lastly, they concluded that this method proves to be a powerful tool to quantify adulteration in cold-pressed WGO with cheap and polished vegetable oils [42] (Table 4).

\section{Quantitative estimation of adulteration in milk}

Cow milk in goat milk: To prevent allergies caused by cows' milk protein mainly among children, to avoid this problem it was generally replaced with soy milk and goat milk. So, there is a need to develop a novel method that is highly sensitive to identify species so as to prevent the threat of allergies due to cows' milk. W Terouzi et al., develop a method to quantify cow milk in goat milk via ATR-FTMIR spectroscopy combination with chemometric technique. Absorption mode was used to take spectra from wavenumber 4000 to $450 \mathrm{~cm}^{-1}$. PLSR model was constructed with $\mathrm{R}^{2}$ of 0.99 and root mean square errors of prediction of less than 1.40078 , LOD $4.202 \%$ and relative prediction errors of 0.0079 . From the obtained results they concluded that the developed method was sound and suitable to quantify the percentage of cow milk (range from 0-30\%) as adulterants in goat milk with no sample preparation. This method was further applicable to quantify the actual proportion of cow milk in adulterated milk [43].

Detection of camel milk adulteration: Souhassou $S$ et al., utilize FT-MIR chemometric methods to identify and quantify adulteration in camel milk with cow milk in a fast and non-destructive way. Pure and adulterated with (1-40\% wt/wt) camel milk with different concentrations was measured. A model was prepared using partial least squares regression method from obtained FTIR spectra at $3000-920 \mathrm{~cm}^{-1}$ region without or with pre-treatment ways such as Gap Segment Derivatives, Standard Normal Variate, Savitzky-Gloay Derivatives, and Noris Gap Derivatives. This method shows reliable results to estimate cow milk in camel milk with $0.9939,3.80 \%$ and $2.595 \%$ of R-square, relative errors and LOD, respectively without pretreatment. So they concluded that the proposed method successfully detects the added cow milk as adulterants in camel milk without the urge of sample pretreatment [44].

Formalin adulteration in cow milk: To protect the deteriorating of milk during transport, formalin is mixed with it as an adulterant but it has a consequence of causing damage to the liver and kidney. Fazal Mabood et al., exploit Near-Infrared spectroscopy in combination with multivariate analysis to detect and quantify the formalin levels in cow milk. They select 4 samples of cow milk with added formalin in 8 different concentrations (in \%) of $0,1,3,5,7$,
9, 11, 13 and 17 formalin. Samples were evaluated in absorption mode in wavenumber from 700-2500 nm. For statistical analysis, three multivariate methods were applied i.e. principal component analysis, partial least discriminant analysis and partial least regression analysis to resultant spectral information from NIR spectroscopy. The principal component analysis model was constructed to see the outcomes of variation between four different cow's milk. From partial least, the discriminant analysis model was applied to check the difference between samples of pure milk and formalin adulterated milk and get $R^{2}=0.969$ and root means square error $=0.086$. After that partial least regression model was built for the quantification of the level of formalin in cow milk and R-square was found to be $93 \%$, Root mean square error of cross validation $=1.38$, root mean square error of prediction $=1.50$ and less $2 \%$ formalin can be quantified. From the obtained results, they conclude that this method was successfully used to quantify the lowest level of formalin (not more the 2\%) present in milk with a non-destructive and cheaper manner and also sample preparation was not much needed [45] (Table 5).

Melamine in milk: Melamine is rich in nitrogenous substances and usually added illegally to boost the content of protein in milk. Available analytical method is a chromatography-based technique, which is laborious, pricey and involves complicated pre-treatments and trained personnel. Hence, it was crucial to develop an analytical method that is reliable and sensitive to verify melamine in human foodstuffs. So, a method was established by Tong $\mathrm{Wu}$ et al., to identify and quantify melamine present in liquor milk using NIR spectroscopy. They select 4000-588 $\mathrm{cm}^{-1}$ Region from obtained spectra to build models as other regions don't have much useful information. Uninformative variable elimination-partial least square was employed to create quantitative models and R-square and ratio of performance to standard deviate were found to be 0.97 and 6.23 . From the result, they concluded that the method can aid an ability for rapid examination of the presence of melamine in milk [46] (Table 5).

Tetracycline residues in cow's milk: Unsafe uses of Tetracycline in dairy and poultry farming may lead to a residue of TCs in milk and tissue, thus causes many negative outcomes to on human health and also affect the marine ecosystem. So, to determine the remaining tetracycline chlortetracycline, and oxytetracycline in cows' milk at $\mu \mathrm{g} / \mathrm{l}$ concentration, a method is developed by Instituto Politécnico Nacional et al., using MIR spectroscopy and chemometric analysis. They record IR spectra from $4000-550 \mathrm{~cm}^{-1}$. They use Soft Independent Modeling of Class Analogy model to separate pure milk 


\begin{tabular}{|c|c|c|c|c|c|c|c|c|c|}
\hline $\begin{array}{l}\text { Sr. } \\
\text { No. }\end{array}$ & Matrix & Analyte & Wavenumber $\left(\mathrm{cm}^{-1}\right)$ & R2 & Error & LOD & LOQ & $\begin{array}{l}\text { Content of } \\
\text { Caffeine }\end{array}$ & Reference \\
\hline 1 & $\begin{array}{c}\text { Green Coffee } \\
\text { Beans }\end{array}$ & Caffeine Content & $\begin{array}{c}2982-2825 \text { (FTIR) } \\
\text { and } 2110-1820 \mathrm{~nm} \\
(\mathrm{NIR})\end{array}$ & $\begin{array}{c}0.993 \text { and } \\
0.994\end{array}$ & - & $\begin{array}{c}0.15 \mathrm{~g} / \mathrm{L} \\
\text { and } 0.3 \mathrm{~g} / \mathrm{L}\end{array}$ & $\begin{array}{c}0.5 \mathrm{~g} / \mathrm{L} \\
\text { and } 1 \mathrm{~g} / \mathrm{L}\end{array}$ & $\begin{array}{l}1.52 \pm 0.09(\% \mathrm{w} / \mathrm{w}) \\
1.50 \pm 0.14(\% \mathrm{w} / \mathrm{w})\end{array}$ & [52] \\
\hline 2 & $\begin{array}{c}\text { Roasted and } \\
\text { Ground Coffee }\end{array}$ & $\begin{array}{l}\text { Coffee Husks, Spent } \\
\text { Coffee Grounds, } \\
\text { Barley, and Corn }\end{array}$ & $\begin{array}{l}1735-700 \\
1135-700\end{array}$ & 0.99 & $\begin{array}{l}\text { Calibration: } 0.69 \% \\
\text { Validation: } 2.00 \%\end{array}$ & - & - & - & [53] \\
\hline 3 & Arabica coffee. & Roasted barley & $4000-600$ & 0.99 & $\begin{array}{l}\text { RMSEP <0.34, Relative } \\
\text { Prediction Errors: } 2.054 \text {. }\end{array}$ & $1.01 \%$ & - & - & [54] \\
\hline 4 & $\begin{array}{l}\text { Roasted } \\
\text { Coffees }\end{array}$ & Defected Beans & $\begin{array}{l}\text { 3100-800 (FTIR) and } \\
1200-2400 \mathrm{~nm} \text { (NIR) }\end{array}$ & $\begin{array}{c}0.891 \text { and } \\
0.953\end{array}$ & $\begin{array}{c}\text { RMSEV: } 0.032 \text { and } \\
0.026\end{array}$ & - & - & - & [55] \\
\hline
\end{tabular}

sample and tetracycline containing milk samples and indicate good separation results. They construct a model for quantitative analysis of tetracycline's residues via Partial Components Regression and Partial Least Squares algorithms. The best model for the predicting an antibiotic level resulted from the Partial Least Square 1 algorithm with $\mathrm{R}^{2}$ between $0.997-0.999$ and standard error of calibration from 1.81-2.95 for calibration set. From the obtained values they concluded that the developed method has the potential to predict the antibiotic concentration of $>10 \mu \mathrm{g} / \mathrm{l}$ in milk and can be applied to confirm the safety of milk [47] (Table 5).

\section{Quantitative estimation of analytes in coffee}

Caffeine content in aqueous solution of green coffee beans: Coffee is considered as the second most significant raw material used in the international market. Due to it's such a commercial significance, quality control is necessary for authorization of caffeine content and inferior products. So, a fast and non-expansive method was developed to determine caffeine present in aqueous green coffee beans by Blen Weldegebreal et al., using ATR-FTIR and fluorescence spectrophotometry. For quantitative analysis ranges from 2982-2825 $\mathrm{cm}^{-1}$ were selected as this region shows good absorption from the obtained spectrum by using FTIR-ATR while using NIR, the region from 2110-1820 nm was selected for quantitative analysis. Caffeine content in green coffee beans employing ATR-FTIR and NIR was found to be $1.52 \pm 0.09(\% \mathrm{w} / \mathrm{w})$ and $1.50 \pm 0.14(\% \mathrm{w} / \mathrm{w})$. R-square, LOD and LOQ using FTIR-ATR and NIR were obtained to be 0.993 , $0.15 \mathrm{~g} / \mathrm{L}$ and $0.5 \mathrm{~g} / \mathrm{L}$ and $0.994,0.3 \mathrm{~g} / \mathrm{L}$ and $1 \mathrm{~g} / \mathrm{L}$, respectively. They concluded that the established method was simple, rapid and low cost for the know of the content of caffeine present in aqueous green coffee beans sample by using ATR-FTIR and NIR spectroscopy and univariate calibration technique can be applied as an alternative technique for determination by reducing the quantity of organic solvent [48] (Table 6).

Adulterants in roasted and ground coffee: Coffee is regularly consumed drink all around the world and become the most targeted product for adulteration. So, a method is proposed by Nádia Reis et al., employing Fourier Transform Infrared Attenuated Total Reflectance Spectroscopy with Partial Least Square regression to determine 4 different adulterants i.e. spent coffee grounds, coffee husks, corn and barley simultaneously in roasted and ground coffee. They tested three different regions from $4000-700 \mathrm{~cm}^{-1}, 1735-700 \mathrm{~cm}^{-1}$, and $1135-700$ $\mathrm{cm}^{-1}$ to construct the PLS model and found that better model for prediction obtained from full spectral range. The roasted coffee was mixed with adulterants at different ranges from 0.5 to $66 \% \mathrm{w} / \mathrm{w}$ with an elevated $\mathrm{R}^{2}$ value of 0.99 for calibration and validation both and less error i.e. $0.69 \%$ and $2.00 \%$ for calibration and validation. The result confirms that the developed method using FTIR-ATR can be used as an important analytical device for quantitative analysis of adulteration present in roasted and ground coffee [49].

Quantification of adulteration in arabica coffee by addition of roasted barley: Analytical methods like chromatographic analysis, UV-Vis spectroscopy and NMR are developed for the analysis of coffee but these techniques need a longer time for the preparation of samples, expensive and extreme production of waste. So, a method that is rapid, consistent and less expensive along with no need for sample preparation was presented by W. Terouzi et al., applying ATR-FTMIR spectroscopy plus chemometric methods to quantify illegally mixing of roasted barley in Arabica coffee. Firstly, they analyzed the data of spectral and reference then consider all the ranges of spectra from $4000-600 \mathrm{~cm}^{-1}$ for construct PLSR model with $\mathrm{R}^{2}$ of 0.99 , Root Mean Square Errors of Prediction of less than 0.34, Limit of Detection of $1.012 \%$ and Relative Prediction Errors as low as 2.054. From the result, they concluded that the present method was effectively used to quantify two mixtures of Arabica coffee in the weight range of $0-45 \%$ of roasted barley. In addition to the method presented is rapid, consistent and less expensive along with no need for sample preparation [50].

Quantification of defects in roasted coffees: In Brazil, the strip picking method may results in immature and overripe of harvesting of beans along with improper processing and storage influence to produce a large quantity of imperfect coffee beans and will impact the quality of the beverage. Ana Paula Craig et al., proposed an FTIR and NIR spectroscopy method for quantitative analysis of defected beans and compare both techniques. They record FTIR and NIR spectra at $3100-800 \mathrm{~cm}^{-1}$ and $1200-2400 \mathrm{~nm}$, respectively. The PLSR model was developed for quantitative analysis. R-square and root mean squared error for the validation model were found to be 0.891 and 0.032 , and 0.953 and 0.026 for FTIR and NIR, respectively. By comparing the two technique NIR show much robust model [51] (Table 6).

\section{Quantitative estimation in beef meat product}

Wild boar meat in meatball formulation: Due to increase cost of beef, a famous Indonesian food Basko or meatball made from beef meat readily substituted with wild boar meat. So, a method is proposed by Any Guntarti et al., to analyze the presence of wild boar meat in beef meatball employing FTIR spectroscopy plus multivariate calibration of Partial Least Square for quantitative study. They analyze wild boar' fat having 100 percent wild boar meat and $100 \%$ beef meat and also the mixture of two and select wavenumbers $1000-1250 \mathrm{~cm}^{-1}$ to aided PLS calibration model for quantitative analysis. From the developed method R-square and RMSEC were found to be 0.998 and $2.00 \%$ (wt $/ \mathrm{wt}$ ), respectively. This developed model for calibration was 
Table 7: Quantitative Estimation in Beef Meat Product.

\begin{tabular}{|c|c|c|c|c|c|c|}
\hline Sr. No. & Matrix & Analyte & Wavenumber $\left(\mathrm{cm}^{-1}\right)$ & $\mathbf{R 2}$ & Error & Reference \\
\hline 1 & $\begin{array}{c}\text { Meatball } \\
\text { Formulation }\end{array}$ & Wild Boar Meat & $1000-1250$ & $0.998 \& 0.986$ & $\begin{array}{c}\text { RMSEC: } 2.00 \% \\
\text { RMSEV: } 5.84 \%(\mathrm{v} / \mathrm{v})\end{array}$ & {$[56]$} \\
\hline 2 & $\begin{array}{c}\text { Meatball } \\
\text { Formulation }\end{array}$ & Rat Meat & $1000-750$ & 0.993 and 0.994 & $\begin{array}{c}\text { RMSEC: } 1.79 \%(w t / w t) \text { and } \\
0.90 \% \%(v / v)\end{array}$ & [57] \\
\hline 3 & Beef Sausage & Rat Meat & $1800-750$ & $\begin{array}{c}0.945 ; 0.991 ; \& 0.983 \text { (calibration) and } \\
0.458 \& 0.983 \text { (validation) }\end{array}$ & $\begin{array}{c}\text { RMSEC: } 2.73 \% ; 1.73 \% \\
\text { \&1.69\% } \\
\text { RMSEV: } 18.90 \%, \& 4.21 \%\end{array}$ & [58] \\
\hline 4 & Dog Meat & Beef Meatball & $1782-1623$ and $1485-659$ & $\begin{array}{l}0.993 \text { (calibration) } \\
0.995 \text { (validation) }\end{array}$ & $\begin{array}{c}\text { RMSEC: } 1.63 \% \\
\text { Standard error of cross- } \\
\text { validation: } 2.68 \%\end{array}$ & [59] \\
\hline 5 & $\begin{array}{c}\text { Chicken in Beef } \\
\text { Meat }\end{array}$ & & $1700-1071$ & $0.899 \& 0.999$ & $\begin{array}{l}\text { RMSEcv: } 1.02 \& 1.74 \text { and } \\
\text { RMSEp: } 0.32 \& 0.73\end{array}$ & {$[60]$} \\
\hline
\end{tabular}

then applied to predict validation sample and R-square and RMSEP were obtained to be 0.986 and $5.84 \%(\mathrm{v} / \mathrm{v})$, respectively. From the result, it was concluded that the proposed model provides accurate results with high R-square and low error for analyzing wild boar meat present in meatball formulation [52] (Table 7).

Rat meat in meatball formulation: Due to increased cost of beef, a famous Indonesian food meatball made from beef meat readily adulterated with rat meat. So, for quantitative analysis, a feasible method was proposed by Halida Rahmania et al., to analyze the existence of rat meat in binary fusion beef meatball products using FTIR spectroscopy plus multivariate calibration of Partial Least Square for quantitative study. They analyze rat' fat having 100 percent rat meat and 100 percent beef meat and also the mixture of two by PLS regression and select wavenumbers $750-1000 \mathrm{~cm}^{-1}$. From the developed method R-square and RMSEC were found to be 0.993 and $1.79 \%$ (wt/wt), respectively. This developed model for calibration was then applied to predict validation sample and R-square and RMSEP were obtained to be 0.994 and $0.90 \% \%(v / v)$, respectively. From the result, it was concluded that the proposed model be able to effectively quantify rat meat present in meatball preparation [53] (Table 7).

Rat meat in beef sausage: Illegal exercise was going on by adulterating rat meat in beef-based sausage because beef meat was quite high. So, using 3 distinct lipid extraction techniques i.e. Bligh and Dyer, Folch, and Soxhlet methods by Ratna Budhi Pebriana et al., proposed a method with an aim to analyze rat meat in sausage employing FTIR with chemometrics. Wavenumber ranges from 750-1800 $\mathrm{cm}^{-1}$ were nominated for PLS modeling for quantitative analysis and coefficient of determination and root mean square error of calibration model for extracted lipid from beef present in rat meat sausages by applying Bligh and Dyer, Folch, and Soxhlet technique was found to be $0.945 \& 2.73 \% ; 0.991 \& 1.73 \% ; 0.992 \& 1.69 \%$, respectively. R-square and root mean square error of prediction for the validation model by applying Folch and Soxhlet method was found to be $0.458 \& 18.90 \%$, and $0.983 \& 4.21 \%$, respectively. For the quantitative analysis, the Soxhlet extraction method was selected as its ability to produce accurate and precise data as compared to another extraction method [54] (Table 7).

Beef meatball adulterated with dog meat: Due to the high price of beef, a famous Indonesian food meatball made from beef meat readily adulterated with less expensive dog meat. So, for recognition and quantification of dog meat present in beef meatball products, a feasible method was proposed by Wiranti Sri Rahayu et al., using FTIR spectroscopy plus multivariate calibration of Partial Least Square for quantitative study. Sample of the meatball was prepared by mixing dog and beef meat in $0-100 \%$ range wt/wt and then extraction was done by using the Folch method. For quantifying dog meat in the meatball PLS calibration model was constructed in the region from $1782-1623 \mathrm{~cm}^{-1}$ and $1485-659 \mathrm{~cm}^{-1}$. By applying the optimised method R-square between actual and predicted FTIR value was obtained to be 0.993 for calibration model and 0.995 for validation model. Root mean square error of calibration and standard error of cross-validation were obtained to be $1.63 \%$ and $2.68 \%$, respectively. From the result, they concluded that the proposed method produces accurate and reliable data for analyzing dog meat present in meatball [55] (Table 7).

Chicken in beef meat: To detect the substitution of beef meat with other cheaper meat product are common nowadays so there is a necessity to establish an accurate analytical method for quality control. So, a method is investigated by Zahra Keshavarzi et al., to quantify chicken present in beef meat mixture. PLS-R and ANN (artificial neural networks) model were prepared for quantitative analysis with the selected regions from $1700-1071 \mathrm{~cm}^{-1}$ on the basis of optimized method R-square, RMSEcv and RMSEp were found to be $0.899 \& 0.999,1.02 \& 1.74$ and $0.32 \& 0.73$, respectively for both models. From the result, it was concluded that ANN model presents much improved results than the PLS-R model [56] (Table 7).

\section{Quantification estimation of cocaine}

Quantification of cocaine in seized powders: The traditional method for screening the presence of cocaine in unidentified powder is a colour test but the problem with these tests is an evaluation of color influence by the worker and also lacks insensitivity. FTIR is an alternative technique for fast screening of cocaine. Spectra provided by FTIR were challenging for interpretation and require specialized expertise and detection to present insufficient sensitivity. To resolve this problem Joy Eliaerts et al., combine FTIR-ATR with Support Vector Machines (SVM), which is a multivariate technique and then compared with PLS-DA technique. They take the spectra of uncontaminated cocaine reference and then three other samples collected from the street and compare them in the fingerprint region from 1800-500 cm-1. Then they investigate the spectra to construct a model for the classification of cocaine and in the second part, they construct a quantitative model, a sample having cocaine are included by using both SVM and PLS-DR techniques. Results obtained from the SVMR model is in between 4.0 and $6.7 \%$ for RMSECs and RMSECVs with $\mathrm{R}^{2}$ for calibration value of $0.95-0.97$ and crossvalidation value of $0.91-0.93$ and by comparing with PLSR present the similar result of $4.9 \%$ to $7.0 \%$ for RMSECs and RMSECVs. RMSEP was found within the range between $5.4 \% \& 7.1 \%$ and the validation 


\begin{tabular}{|c|c|c|c|c|c|c|}
\hline Sr. No. & Matrix & Analyte & Wavenumber $\left(\mathrm{cm}^{-1}\right)$ & R2 & Errors & Reference \\
\hline 1 & Seized Powders & Cocaine & $1800-500$ & $\begin{array}{c}\text { 0.95-0.97 (Calibration) } \\
\text { s0.91-0.93 (Cross-validation) } \\
0.92 \text { (Prediction) }\end{array}$ & $\begin{array}{l}\text { RMSECS: } 4.0 \\
\text { RMSECS: } 6.7 \% \\
\text { RMSEP: } 6.3 \% .\end{array}$ & [61] \\
\hline 2 & Seized Drug Samples & Cocaine Hydrochloride & $\begin{array}{c}500 \text { and } 800 \\
1400 \text { and } 1800\end{array}$ & $0.904 \& 0.914$ & $\begin{array}{l}\text { RMSEC: } 2.89 \& 2.70 \% \\
\text { RMSEP: } 2.47 \& 2.77 \% \\
\text { REPCal: } 3.94 \& 3.66 \\
\text { REPVal: } 9.11 \& 9.94\end{array}$ & [62] \\
\hline 4 & Impregnated Materials & Cocaine & $\begin{array}{l}6136.5-5882.0 \\
5876.2-5523.3 \\
5197.4-4142.5\end{array}$ & - & $\begin{array}{l}\text { RMSEC: } 1.12 \text { and } 1.54 \% \mathrm{w} / \mathrm{w} \\
\text { RMSECV: } 0.43 \text { and } 1.94 \% \mathrm{w} / \mathrm{w}\end{array}$ & {$[64]$} \\
\hline
\end{tabular}

sample with $\mathrm{R}^{2}$ and RMSEP obtained to be 0.92 and $6.3 \%$. So, they concluded that the proposed method to detect cocaine and reliable analysis in various mixtures of cocaine content with a user-friendly and fast methodology to categorize and quantify cocaine present in seized powders (57). The results have been depicted in (Table 8).

Cocaine hydrochloride in seized drug samples: In drug samples, the determination of cocaine is a crucial job for an organization dealing with the law like the Brazilian Federal Police. So, an approach was developed for quantitative estimation of cocaine $\mathrm{HCl}$ in drug samples by Tatiane S. Groberio et al., based on FTIR-ATR acquired spectra and PLSR. Wavenumber in between 500 and 800 $\mathrm{cm}^{-1}$ and 1400 and $1800 \mathrm{~cm}^{-1}$ have been observed as high value for the regression coefficients i.e. 0.904 (for reflectance) \& 0.914 (for absorbance). In reflectance mode RMSEC, RMSEP, REP Cal $_{\text {and }}$ REPval was found to be 2.89,2.47, 3.94 and 9.11, respectively while in absorbance mode RMSEC, RMSEP, REP $_{\text {Cal }}$ and REPval was found to be $2.70,2.77,3.66$, and 9.94 . From the result they concluded that the established technique was suitable for the analysis of cocaine $\mathrm{HCl}$ in drug sample without preparing sample with prediction errors on an average of $3.00 \%(\mathrm{~m} / \mathrm{m})$, precision of $1.50 \%(\mathrm{~m} / \mathrm{m})$ and minimum detectable concentration of $13 \%(\mathrm{~m} / \mathrm{m})$. This method can contribute as a fast and accurate detection of unauthorised use of illegal drug and hence, useful for the judiciary system and society [58].

Cocaine in seized drug samples: The previous method to quantify cocaine in seizures was performed by gas chromatography with flame ionization detector but it has a disadvantage like a sample preparation was complex, high analysis cost and damage of samples was quite prominent. So, a simpler method was presented by Tatiane $S$ Groberio et al., for the quantitative estimation of cocaine in seized materials and its prominent adulterants using a combination of IR spectroscopy and PLSR method. They develop a Multivariate calibration method by using partial least squares regression to know the amount of cocaine and its prominent substitution in seized samples and spectra were taken from 4000 and $400 \mathrm{~cm}^{-1}$. From the developed quantitative model value for RMSEC and RMSEP was obtained to be 3.02 and 2.79, respectively, Precision $=2.29$, and $\mathrm{R}^{2}$ for validation $=0.946$. From the result, they concluded that the established method has the ability to quantify the content of cocaine in a sample and also the present advantage of the ease in sample preparation, no requirements of solvent and also offer low analysis cost with high throughput analytical as compared to GC-FID technique [59] (Table 8).

Cocaine in impregnated materials: Due to insufficient ability of the previous method for the quantification of content of cocaine, Clara
Perez-Alfonsob et al., estimate the ability of infrared spectroscopy with PLSR method for the quantification of cocaine in impregnated materials. Wavenumber range from 3108-2370, 1392-1267, 989-889 and $654-542 \mathrm{~cm}^{-1}$ show the best model for prediction using PLSATR-MIR while for PLS-DR-NIR, and model was constructed in wavenumber region from 6136.5-5882.0, 5876.2-5523.3, and 5197.4$4142.5 \mathrm{~cm}^{-1}$. In both model roots, mean square error for calibration and cross-validation of $1.12 \% \mathrm{w} / \mathrm{w}$ and $1.54 \% \mathrm{w} / \mathrm{w} ; 0.43 \% \mathrm{w} / \mathrm{w}$ and $1.94 \% \mathrm{w} / \mathrm{w}$, respectively. The obtained result then was statistical compared with RMSEP obtained from reference method of $0.60 \%$ $\mathrm{w} / \mathrm{w}$ for MIR and $0.88 \% \mathrm{w} / \mathrm{w}$ for the NIR technique. They applied this method to quantify the cocaine present in pulp paper, impregnated clothes and foam [60] (Table 8).

\section{Quantification estimation of lipids, fats, and oil}

Total lipid content in oleaginous yeasts: Oleaginous yeasts are the source for lipids used as food, feed and production of biofuel products. Volha Shapaval et al., establish a method for predicting the content of lipid in oleaginous yeasts by non-offensive highoutput FTIR spectroscopy. The IR regions from $3100-2800 \mathrm{~cm}^{-1}$ and $3100-2800 \mathrm{~cm}^{-1}$ together with $1800-700 \mathrm{~cm}^{-1}$ were observed for total lipid content prediction. The coefficient of determination for calibration model to predict fatty acid profie was found to be in range between 0.92 and 0.62 . $\mathrm{R}^{2}$ of independent test set for fatty acid profile prediction was found to be 0.53 and 0.79 , RMSECV $=4.12$ and RMSE $_{\text {Test }}=19.00$. Total lipid content was found to be 1.000. From the result, they concluded that the developed method when merged with multivariate data analysis permits us to quantitatively predict the total lipid content with non-invasive, rapid, reproducibly and precisely. By using this method, we can also detect several lipid fractions as free fatty acids or triacylglycerols and also for evaluation of the entire biochemical profile of cells. Numerous strains of yeast contain a large lipid accumulation were recognized [61] (Table 9).

Free fatty acids in extra virgin olive oils: Titration is a commonly used method to measure content FFA. Even though this method is quite simple but requires a longer time to process and requires a large quantity of chemicals which are generally costly, lethal and generate a lot of chemical waste. FTIR spectroscopic method is frequently employed for confirmation and quantification of oils and fats. Ismail Tarhan et al., develop an FTIR spectroscopy method using different modes of absorption merge with the chemometrics method for the quantification of FFA in chemometrics techniques in extra virgin olive oils. Reflection and transmission (the two absorption mode), normal and first derivative spectra (two pre-treatments) were examined in different spectral regions of infrared. Normal spectra show the best 
Table 9: Quantification Estimation of Lipids, Fats and Oil.

\begin{tabular}{|c|c|c|c|c|c|c|c|}
\hline Sr. No. & Matrix & Analyte & $\begin{array}{l}\text { Wavenumber } \\
\left(\mathrm{cm}^{-1}\right)\end{array}$ & R2 & Errors & $\begin{array}{l}\text { Content of analyte } \\
\text { (\%) }\end{array}$ & Reference \\
\hline 1 & Oleaginous Yeasts & Total Lipid & $\begin{array}{c}3100-2800 \\
1800-700\end{array}$ & $\begin{array}{c}0.92 \text { to } 0.62 \& 0.53 \text { and } 0.79 \\
\text { (test set) }\end{array}$ & $\begin{array}{c}\text { RMSE }_{\mathrm{CV}}: 4.12 \text { RMSETest: } \\
19.00\end{array}$ & 1 & [65] \\
\hline 2 & $\begin{array}{l}\text { Extra Virgin Olive } \\
\text { Oils }\end{array}$ & $\begin{array}{l}\text { Free Fatty } \\
\text { Acids }\end{array}$ & $\begin{array}{l}1724-1646 \\
3324-3023\end{array}$ & 0.99979 & $\begin{array}{l}\text { RMSEC: } 0.00441 \\
\text { RMSECV: } 0.0107\end{array}$ & More than 0.8 & {$[66]$} \\
\hline 3 & Potato Chips & Fat & $\begin{array}{l}4130-4380 \\
5300-6300\end{array}$ & $0.992,0.995 \& 0.9823$ & - & 25 to 38 & {$[67]$} \\
\hline
\end{tabular}

prediction of results by using transmission mode having the highest $\mathrm{R}^{2}$ value of 0.99979 , lowest root mean square error of calibration and root mean square error of cross-validation was 0.00441 and 0.0107 respectively at $1724-1646$ and $3324-3023 \mathrm{~cm}^{-1}$ spectral region. FFA content in marketed sample was found to be more than $0.8 \%$ FFA. Hence, they concluded that developed methods if is rapid, environment-friendly, and can the recovery for the quantification of FFA content in EVOOs in olive oil industries [62] (Table 9).

Determination of fat in potato chips: Fat content in food products is an essential parameter during the quality control process. Previously Soxhlet method is used for this persistence, which is generally time-consuming and a little expensive. So, Sylwester Mazurek et al., demonstrate that IR spectroscopy can successfully substitute the extraction method. Partial least squares calibration models were formed from obtained spectra at 500-920, 1060-1800 and $2700-3040 \mathrm{~cm}^{-1}$ range. PLS factors were created for DRIFT (is 7) and singular reflectance techniques and correlation coefficient values were found to be 0.992 and 0.995 respectively. SR model shows improved quality than that of built utilizing DRIFT data. One more PLS model was eracted at spectral range from 4130 to 4380 and 5300 to 6300 $\mathrm{cm}^{-1}$ using NIR/DRIFT spectra and $\mathrm{R}^{2}$ was obtained to be 0.9823 . Fat content by using these 3 calibration models on chips prepared in the laboratory was 25 to $38 \%$ fat. For quantification lowest errors were found from DRIFT/MIR method [63] (Table 9).

\section{Quantification of sugar}

Simple sugars in local and floridian mango (Mangifera Indica L): Mangoes are high nutritious value and they vary in the level of sugar content in them depending on conditions provided during its cultivation. Kennedy Olale et al., established an approach for evaluation for the fructose and glucose sugars by means of Diffuse Reflectance Infrared Fourier Transform (DRIFT) spectroscopy in the Kenyan mangoes pulp. The need for a new method arrived as most of the methods for analysis of sugar content were mostly performed by HPLC methods, which were expensive and consumed a lot of time. Kennedy with the team built the PLSR model in range $4000-500 \mathrm{~cm}^{-1}$ for fructose and for glucose $1500-750 \mathrm{~cm}^{-1}$. A factorial AOVA was used to compare the outcomes of three different locations, four cultivar types, the position of fruit (inside/outside), and their interactions with glucose and fructose content. PLS range was $\mathrm{R}^{2}=0.80$ for glucose, SECV (standard error of cross-validation) $=0.55$ and RPD (residual predictive deviation) $=11.52$. For fructose $\mathrm{R}^{2}=0.70, \mathrm{RPD}=11.52$ and $\mathrm{SECV}=0.28$. So, DRIFT can be a potential technique for the analysis of glucose and fructose content in mango fruits [64] (Table 10).

Sucrose content in fruit juices: Previous methods used for quantification of sugar in fruit juice are tedious and require complex sample pre-treatment steps. Moreover, they require organic reagents that are hazardous and need special care and high cost for their storage and disposal. So, methods which can be rapid and can reduce cost are of high prominence as some manufacturers try to cheat consumers also to gain the advantage over other manufacturers using adulterated fruit juices, false label claims etc. Reshma Nair et al., used FT-IR to quantify sucrose present naturally in mango, grape and pineapple juices. Between 1057 and $1061 \mathrm{~cm}^{-1}$ range, sucrose spectral peak was observed. $\mathrm{R}^{2}$ was found to be 0.997 from $1-5 \%$ concentration of sucrose sample. The spectra were studied in the wavenumber range of $4000-500 \mathrm{~cm}^{-1}$ for all three samples and a absorption band at 1058 $\mathrm{cm}^{-1}$ was studied. The amount of sugar present in grapes, mango and pineapple were found to be $0.85 \%, 17.32 \%$ and $6.26 \%$, which was obtained by solving linear equations from peak area calibration curve. The method is very as analysis could be performed in 1-2 min. So, this method can provide accurate, rapid and non-destructive sucrose content determination without any sample preparation. Out of the three samples analyzed mango was found to contain the highest concentration of sucrose content [65] (Table 10).

Quantification of artificial sweeteners: All the countries have presented their own regulation for limiting the maximum level of sweeteners in food articles to promote consumer health. So as to present a method which is fast, accurate and environmentally friendly and can be simply used for quality control of sugar content in industries, Yu-Tang Wang et al., proposed a method utilizing FTIR with multivariate analysis and quantified 5 artificial sweeteners including sodium saccharin, sodium cyclamate, sucralose, aspartame and acesulfame-K. The identifying bands selected were 1196-1146 $\mathrm{cm}^{-1}$ and $1412-1277 \mathrm{~cm}^{-1}$ for sucralose, $1258-1119 \mathrm{~cm}^{-1}$ for sodium cyclamate, $1212-1203 \mathrm{~cm}^{-1}, 1270-1245 \mathrm{~cm}^{-1}$ and $1328-1307 \mathrm{~cm}^{-1}$ for sodium saccharin, $1069-1065 \mathrm{~cm}^{-1}, 1200-1142 \mathrm{~cm}^{-1}$ and 1428-1269 $\mathrm{cm}^{-1}$ for acesulfame-K and $1410-1330 \mathrm{~cm}^{-1}$ for aspartame. A single sweetener sample was used optimal prediction performance with an $\mathrm{R}^{2}$ value between 0.9981-0.9996 and RMSEP between 0.012-0.0013. The $\mathrm{R}^{2}$ value and RMSEP value for a mixture of two sweeteners were 0.9397-0.9998 and 0.062-0.0014 respectively [66] (Table 10).

Carbohydrate excipients in gardeniae fructus: Formula granule is a preparation of old Chinese remedy made of single herbal medicine decoction by spray drying. Due to the addition of excess amount of carbohydrate excipients commercial formula granules, its efficacy and safety suffer. Jianbo Chen et al., make use of ATR-FTIR spectroscopy for the purpose of detecting carbohydrate excipients present in formula granules of gardenia fructus. Formula granules can estimate directly without pre-treatment or chemical reagents using attenuated total reflectance. The commonly used excipient in marketed formula granules is dextrin in different concentrations. As the content of dextrin increased there occurs a simultaneous increase in absorption band in the wavenumber range from $1200-900 \mathrm{~cm}^{-1}$. Comparing nearby peaks in the second derivative spectra also showed an increase in peaks near $985 \mathrm{~cm}^{-1}, 1075 \mathrm{~cm}^{-1}$ and $1152 \mathrm{~cm}^{-1}$ region. Finally using the PLS model region $1500-800 \mathrm{~cm}^{-1}$ of ATR-FTIR 


\begin{tabular}{|c|c|c|c|c|c|c|c|}
\hline Sr. No. & Matrix & Analyte & $\begin{array}{l}\text { Wavenumber } \\
\left(\mathrm{cm}^{-1}\right)\end{array}$ & R2 & Errors & Content of analyte & Reference \\
\hline 1 & $\begin{array}{l}\text { Local and Floridian } \\
\text { Mango }\end{array}$ & $\begin{array}{l}\text { Simple } \\
\text { Sugars }\end{array}$ & $1500-750$ & 0.8 & $\begin{array}{l}\text { SECV: } 0.55 \\
\text { RPD: } 11.52 .\end{array}$ & - & [68] \\
\hline 2 & $\begin{array}{l}\text { Grapes, Mango \& } \\
\text { Pineapple }\end{array}$ & Sucrose & 1058 & 0.997 & - & $\begin{array}{c}0.85 \%, 17.32 \% \& \\
6.26 \%\end{array}$ & [69] \\
\hline 3 & Artificial sweeteners & Sugar & $\begin{array}{l}1196-1146 \\
1412-1277 \\
1258-1119 \\
1212-1203 \\
1270-1245 \\
1328-1307 \\
1069-1065 \\
1200-1142 \\
1428-1269\end{array}$ & $\begin{array}{c}0.9981-0.9996 \& 0.9397- \\
0.9998\end{array}$ & $\begin{array}{c}\text { RMSEP: } 0.012-0.0013 \& 0.062- \\
0.0014\end{array}$ & (2) & [70] \\
\hline 4 & Gardeniae Fructus & Dextrin & $1200-900$ & 0.9911 & SEP: $2.2 \%$. & - & [71] \\
\hline
\end{tabular}

Table 11: Quantification of Adulterants in Plant and Animal based Product.

\begin{tabular}{|c|c|c|c|c|c|c|c|c|}
\hline Sr. No. & Matrix & Analyte & $\begin{array}{c}\text { Wavenumber } \\
\left(\mathrm{cm}^{-1}\right)\end{array}$ & R2 & Errors & LOD & LOQ & Reference \\
\hline 1 & Surimi & Starch & $1200-950$ & 0.9856 & RMSEP: 5.64 & - & - & [72] \\
\hline 2 & Turmeric & Chromium (VI) & $946,885 \& 755$ & 0.94 & - & $1.22 \mu \mathrm{gmL}^{-1}$ & $4.03 \mu \mathrm{gmL}^{-1}$ & [73] \\
\hline 3 & Paprika powder & Sudan dye & $1800-650$ & 0.98 & $\begin{array}{l}\text { RMSEC: } 0.026 \% \\
\text { RMSEV: } 0.05 \%\end{array}$ & - & - & [74] \\
\hline 4 & $\begin{array}{l}\text { Rambak } \\
\text { Crackers }\end{array}$ & Lard & $1200-1000$ & $0.946 \& 0.997$ & $\begin{array}{l}\text { RMSEC: } 2.77 \% \\
\text { RMSEP: } 2.77 \%\end{array}$ & - & - & [75] \\
\hline 5 & $\begin{array}{l}\text { Stingless Bees } \\
\text { Honey }\end{array}$ & $\begin{array}{c}\text { Fructose, Glucose, Sucrose, Corn } \\
\text { Syrup and Cane sugar }\end{array}$ & $1180-750$ & $\begin{array}{l}0.997-0.999 \\
\text { (calibration) } \\
0.994-0.999 \\
\text { (prediction) }\end{array}$ & $\begin{array}{l}\text { Error of calibrations: } \\
0.686-1.087 \% \\
\text { SEP: } 0.581-1.489 \%\end{array}$ & - & - & {$[76]$} \\
\hline
\end{tabular}

was selected which $\mathrm{R}^{2}$ value 0.9911 and SEP of $2.2 \%$. Sensitivity and specificity are often limited for this model as there is an overlapping of herbal extract and carbohydrate signal. However, FTIR still be useful as promising technique for cheap, simple and fast analysis of carbohydrate excipients in Gardeniae Fructus [67] (Table 10).

\section{Quantification of adulterants in plant and animal-based product}

Starch in surimi: Surimi is a source of high nutrition food product but due to drain in fishery means adulteration in surimi foodstuff with plant and animal proteins, there is a serious need to identify these substances. So, a method is proposed by Shi-Wei Hou et al., for quantitative and qualitative analysis of starch in surimi by exploring Fourier transforms IR spectroscopy with IR imaging spectroscopy. For the analysis and prediction of content of starch present in surimi, a quantitative model was constructed at wavenumber from 1200-950 $\mathrm{cm}^{-1}$ and results in a reliable R-square of 0.9856 and root mean square error of prediction of 5.64. So, they conclude that the developed method can be applied for the recognition quantitative detection of content of starch in surimi [68] (Table 11).

Chromium (VI) in turmeric samples: Chromium (VI) is lethal and carcinogenic in nature and impact on metabolic processes adversely. So, the estimation of Cr (VI) in complex matrices in foodstuff was essential. So, a method was proposed by employing cloud point extraction so as to determine the presence of Cr (IV) in foodstuff by Swapnil Tiwari et al., explore DRS-FTIR analysis. For quantitative analysis selection of peak was done by comparing extracted analyte spectra and pure spectra of $\mathrm{Cr}$ (IV) and found that $946 \mathrm{~cm}^{-1}$ and $885 \mathrm{~cm}^{-1}$, and $755 \mathrm{~cm}^{-1}$ show characteristic bands in IR spectra of $\mathrm{Cr}$ (IV) ions. $\mathrm{R}^{2}$ (in the range of 1-100 $\mu \mathrm{g} \mathrm{mL}^{-1}$ ), LOD, and LOQ were achieved to be $0.94,1.22 \mu \mathrm{g} \mathrm{mL}^{-1}$, and $4.03 \mu \mathrm{g} \mathrm{mL}-1$
L, respectively. From the result, they concluded that the proposed method has the ability to apply as an alternative for analyzing $\mathrm{Cr}$ (VI) in a simple and rapid way. The future perspective of the present method is that the method can use for the analysis of extremely complex and heterogenous substances [69] (Table 11).

Sudan dye in paprika powder: Marketed products containing paprika and chili are frequently adulterated with Sudan dye for economic purpose. An analytical method using FTIR spectroscopy is frequently employed for quality control and safety analysis of foodstuff. So, Santosh Lohumi et al., utilize the FTIR technique for quick detection of Sudan dye in paprika powder. They construct a model from SNV pre-processed FTIR spectra and select spectral range from $1800-650 \mathrm{~cm}^{-1}$ by utilizing HLA/GO multivariate calibration with a high $\mathrm{R}^{2}$ of 0.98 and root mean square error $0.026 \%$ was obtained for calibration set while for validation set $R^{2}$ and RMSE (root mean square error) was obtained to be 0.97 and $0.05 \%$, respectively. From the obtained result they concluded that the developed technique using FTIR in combination to HLA/GO has an advantage over LC technique that's why choose as an alternative technique and also considered as a useful technique for future quality control and recognition of adulterants in powdered species, especially in developing country were species are sold without proper labeling and branding [70] (Table 11).

Lard in "rambak" crackers: Rambak cracker is a traditional diet of Indonesia prepared from the skin of different animals like buffalo, pig or cattle skin. Substitution of pigskin used to prepare rambak crackers with other cheaper animal skin like cow skin. A method is proposed by Yuny Erwanto et al., to analyze the extracted lard from rambak cracker employing FTIR spectroscopy and chemometrics analysis of PLS (partial least square). To quantify lard obtained 


\begin{tabular}{|c|c|c|c|c|c|c|c|c|c|}
\hline $\begin{array}{l}\text { Sr. } \\
\text { No. }\end{array}$ & Matrix & Analyte & $\begin{array}{l}\text { Wavenumber } \\
\left(\mathrm{cm}^{-1}\right)\end{array}$ & R2 & LOD & LOQ & Errors & Concentration of analyte & Reference \\
\hline 1 & $\begin{array}{c}\text { Antimicrobial } \\
\text { Food } \\
\text { Packaging }\end{array}$ & $\begin{array}{l}\text { Carvacrol, } \\
\text { Thymol \& } \\
\text { p-cymene }\end{array}$ & $\begin{array}{l}1125-1095 \\
1170-1140 \\
1050-1017\end{array}$ & $\begin{array}{c}0.982-0.923, \\
0.978-0.948, \& \\
0.988-0.910\end{array}$ & - & - & $\begin{array}{l}\text { SEC: } 0.961,0.920 \\
\& 0.904 \\
\text { SEP: } 0.92,30.948 \\
\& 0.910\end{array}$ & $\begin{array}{c}74.4 \pm 0.2 \%(w / w) \\
7.9 \pm 0.3 \%(w / w) \\
6.3 \pm 0.25 \%(w / w)\end{array}$ & [77] \\
\hline 2 & $\begin{array}{l}\text { Modified } \\
\text { Asphalt }\end{array}$ & SBS Content & 1400 to 800 & - & - & - & $\begin{array}{c}\text { RMSEP: } 0.061 \& \\
0.088\end{array}$ & - & [78] \\
\hline 3 & $\begin{array}{c}\text { Poultry Egg- } \\
\text { Yolk }\end{array}$ & $\begin{array}{c}\text { Ciprofloxacin \& } \\
\text { Norfloxacin }\end{array}$ & $1627 \& 1026$ & $\begin{array}{l}0.998 \& 0.997 \\
0.995 \& 0.994\end{array}$ & $\begin{array}{c}0.032 \text { and } \\
0.028 \\
\mathrm{ngmL}^{-1}\end{array}$ & $\begin{array}{c}1.551 \text { and } \\
0.194 \\
\mathrm{ngmL}^{-1}\end{array}$ & 0.000 & $\begin{array}{c}\text { CIP: } 0.087 \pm 0.038 \\
0.410 \pm 0.012,0.412 \pm 0.008 \\
0.251 \pm 0.345 \& 0.495 \pm 0.022 \\
\text { NOR: } 0.070 \pm 0.038 \\
0.498 \pm 0.012,0.196 \pm 0.077, \& \\
0.336 \pm 0.046 \text { (from different } \\
\text { sources) }\end{array}$ & [79] \\
\hline 4 & Gasoline & $\begin{array}{l}\text { Kerosene; } \\
\text { Diesel; } \\
\text { Naphtha \& } \\
\text { Premix }\end{array}$ & $\begin{array}{c}650 \text { and } 551 ; \\
1472 \text { to } 1447 ; \\
3501 ; \& 1503 \text { to } \\
1361\end{array}$ & $\begin{array}{c}0.973,1.000 \\
0.984, \& 0.997\end{array}$ & - & - & $\begin{array}{c}\text { RMSEC: } 0.79182, \\
\text { 2.7909, } 3.023 \\
0.15986,0.1236 \\
\text { RMSECV: } 2.3078 \\
4.1054,1.9338 \\
0.99811 \\
\text { RMSEP: } 2.451 \\
2.8607 \& 2.3724\end{array}$ & $\begin{array}{l}17-33 \% \mathrm{v} / \mathrm{v} \\
38.908 \mathrm{v} / \mathrm{v} \\
25-34 \% \mathrm{v} / \mathrm{v}\end{array}$ & [80] \\
\hline
\end{tabular}

from rambak cracker, wave number from $1200-1000 \mathrm{~cm}^{-1}$ was used positively with the coefficient of determination for calibrations were 0.946 and root mean square error of calibration was $2.77 \%$. R-square and root mean square error of prediction was obtained to be 0.997 and $2.77 \%$, respectively. So, they concluded that the proposed method was fast and reliable to quantify lard in rambak crackes [71] (Table 11).

Fructose, sucrose, glucose, corn syrup and cane sugar in stingless bees honey: Kuan Wei Se et al., develops an approach to support detection and quantification of 5 different adulterants like sucrose, glucose, fructose, present in the honey of stingless bees (Heterotrigona itama) by exploring FTIR in combination with chemometrics analysis. Quantification of adulterants (sucrose, fructose, glucose, corn syrup and cane sugar) in honey was done by employing PLSR and utilizes $1180-750 \mathrm{~cm}^{-1}$ range from the first derivative spectra and $\mathrm{R}^{2}$ for calibration set was found in the range of 0.997-0.999 while 0.994-0.999 for prediction set. By applying the optimised method, an acceptable range from 0.686-1.087\% and $0.581-1.489 \%$ for error of calibrations and standard error of predictions, respectively. Hence demonstrate that the developed method shows good predictive ability. So, they concluded that the method was accurate and rapid as it requires 7-8 min to identify and quantify presence of adulterants in honey as compared to standard AOAC method 998.12 which requires 3 hours [72] (Table 11).

\section{Miscellaneous}

Active compounds of essential oils in antimicrobial food packaging: Andrea Carolina Solano Valderrama et al., develop a method for fast and simple determination of chief essential oil like carvacrol, thymol, and p-cymene in antimicrobial LDPE films in combination with oregano and thyme by employing FTIR spectroscopy. For quantitative estimation of these components characteristic IR ranges at $1125 \mathrm{~cm}^{-1}$ to $1095 \mathrm{~cm}^{-1}, 1170 \mathrm{~cm}^{-1}$ to 1140 $\mathrm{cm}^{-1}$ and $1050 \mathrm{~cm}^{-1}$ to $1017 \mathrm{~cm}^{-1}$ were selected using PLS analysis. $\mathrm{R}^{2}$ of calibration and validation was found to be 0.982 and $0.923 ; 0.978$ and 0.948 and 0.988 and 0.910 for carvacrol, thymol and p-cymene, respectively. Standard Error Calibration (SEC) and Standard Error of Prediction (SEP) was found to be $0.961,0.920, \& 0.904$ and $0.92,3$
0.948, \& 0.910 for carvacrol, thymol and p-cymene, respectively. From the result, they concluded that the described method was effectively practiced to envisage the content of active constituents (carvacrol, thymol and p-cymene) present in essential oils: oregano and thyme. This method was further applied in industry in place of extraction, distillation and blend procedure for the above stated essential oils to reveal the carvacrol, thymol and p-cymene content present in commercial products [73] (Table 12).

SBS Content in modified asphalt: To assess the functioning of modified asphalt, it is essential to quantify styrene-butadienestyrene present in modified asphalt. So, Kang Wang et al., proposed a methodology using FTIR along with the help of solvent cast film and chemometrics techniques for the implementation of quantitative analysis of SBS (quantify styrene-butadiene-styrene) in modified asphalt. The select wavenumber from $1400-800 \mathrm{~cm}^{-1}$ provide good model for calibration with accurate value for determination $=4.206 \%$ and lowest standard deviation $=0.196$. From the obtained result, they concluded that the method indicates good predictability to quantify the content of SBS [74] (Table 12).

Fluoroquinolone antibiotics in poultry egg-yolk: Ramsingh Kurreya et al., describe a new methodology for monitoring ciprofloxacin and norfloxacin antibiotic quantification in poultry egg yolks by employing diffuse reflectance-Fourier transforms infrared spectroscopy as the previously developed methods was consumed more time, a large amount of solvent. Absorption peak at $1627 \mathrm{~cm}^{-1}$ and $1026 \mathrm{~cm}^{-1}$ were utilized as characterize band for ciprofloxacin and norfloxacin for optimization and quantification, respectively, with $\mathrm{R}^{2}$ value 0.998 and 0.997 for ciprofloxacin (against peak area and peak height, respectively) and 0.995 and 0.994 for norfloxacin (against peak area and peak height, respectively). LOD obtained was 0.032 and $0.028 \mathrm{ng} \mathrm{mL}^{-1}$ ciprofloxacin and norfloxacin while LOQ of 1.551 and $0.194 \mathrm{ng} \mathrm{mL}^{-1}$. From the result, they concluded that the obtained method shows its ability to perform analysis with high-throughput in food samples by a simple, sensitive and suitable procedure [75] (Table 12).

Adulteration of kerosene, diesel, naphtha, and premix in 
gasoline: Exercises of criminal act by adulterating fuel (gasoline) are quite general. Hence, there is a need to develop a consistent and cheaper method for the recognition of adulteration in fuel as the current methods are quite expensive for developing countries to implement it. So, a technique was established by J Dadson et al., for the investigation of adulterants like diesel, kerosene, naphtha, and premix in gasoline quantitatively by employing the combination of FTIR and a multivariate technique. They prepare a synthetic mixture of gasoline plus adulterants in different proportions, which were applied for model calibration. Soft Independent Modeling Class Analogy model was established for the prediction of different categories of adulterants with error rate for kerosene and naphtha of $6.25 \%$, for premix was $12.5 \%$ and $0 \%$ for diesel contaminated sample. Then they develop a PLS model to quantify: kerosene in gasoline; diesel in adulterated gasoline; naphtha in adulterated gasoline; and premix in adulterated gasoline and selected spectra ranges are: 650 and $551 \mathrm{~cm}^{-1} ; 1472-1447 \mathrm{~cm}^{-1} ; 3501 \mathrm{~cm}^{-1}$; and $1503-1361 \mathrm{~cm}^{-1}$ as these regions show best for calibration of the model with $\mathrm{R}^{2}$ of $0.973 ; 1.000$; 0.984; and 0.997, respectively. Different commercial gasoline from Ghana was analyzed and the concentration of kerosene was in the range of $17-33 \% \mathrm{v} / \mathrm{v}$, for diesel $=38.908 \mathrm{v} / \mathrm{v}$, premix was in the range of $25-34 \% \mathrm{v} / \mathrm{v}$ and no naphtha were detected. So, they concluded that the method was a feasible, low-priced and fast methodology for the quantitative recognition of gasoline adulterants [76] (Table 12).

\section{Conclusion}

FTIR spectroscopy with chemometrics techniques has great applications in study of various aspects of pharmaceuticals and foodstuffs. This review has emphasised the range of FTIR and chemometrics techniques and their principles, sample preparation method, sample handling techniques and applications in quantitative study. In addition, this technique offers a convenient and fast quantitative study to investigate varieties of analytes like API, adulterants, caffeine, cocaine, lipids, fats \& oils, sugar and other analytes.

\section{Acknowledgement}

The authors are thankful to the to Mr. Praveen Garg, Chairman and Prof. (Dr) GD Gupta, Director cum Principal, ISF College of Pharmacy, Moga, Punjab for his continuous support and encouragement.

\section{References}

1. Clark JH, Macquarrie DJ. Handbook of green chemistry and technology: John Wiley \& Sons. 2008.

2. Khanmohammadi M, Mozaffari F, Garmarudi AB, Rouchi MB. Cardiovascular biodiagnosis by infrared spectroscopy through choline determination. Analytical Methods. 2015; 7: 8561-8567.

3. Lima JGS, de Marco BA, Salgado HR N. Green analytical method for quantification of Secnidazole in tablets by Fourier-Transform Infrared Spectroscopy (FTIR). Drug Analytical Research. 2018; 2: 14-19.

4. Invernizzi C, Rovetta T, Licchelli M, Malagodi M. Mid and near-infrared reflection spectral database of natural organic materials in the cultural heritage field. International journal of analytical chemistry. 2018; 2018.

5. He X, Liu X, Nie B, Song D. FTIR and Raman spectroscopy characterization of functional groups in various rank coals. Fuel. 2017; 206: 555-563.

6. Amir RM, Anjum FM, Khan MI, Khan MR, Pasha I, Nadeem M. Application of Fourier Transform Infrared (FTIR) spectroscopy for the identification of wheat varieties. Journal of food science and technology. 2013; 50: 1018-1023.

7. Munajad A, Subroto C. Fourier Transform Infrared (FTIR) spectroscopy analysis of transformer paper in mineral oil-paper composite insulation under accelerated thermal aging. Energies. 2018; 11: 364.

8. Stuart B. Infrared spectroscopy. Kirk-Othmer encyclopedia of chemical technology. 2000.

9. Hagemann LT, McCartney MM, Fung AG, Peirano DJ, Davis CE, Mizaikoff B. Portable combination of Fourier transform infrared spectroscopy and differential mobility spectrometry for advanced vapor phase analysis. Analyst. 2018; 143: 5683-5691.

10. El Fels L, Zamama M, Hafidi M. Advantages and limitations of using FTIR spectroscopy for assessing the maturity of sewage sludge and olive oil waste co-composts. Biodegradation and bioremediation of polluted systems. New advances and technologies In Tech. 2015: 127-144.

11. Cui H, Abu-Siada A, Li S, Islam S, editors. Correlation between dissolved gases and oil spectral response. $20171^{\text {st }}$ International Conference on Electrical Materials and Power Equipment (ICEMPE). 2017: IEEE.

12. Liang P, Chen C, Zhao S, Ge F, Liu D, Liu B, et al. Application of Fourier transform infrared spectroscopy for the oxidation and peroxide value evaluation in virgin walnut oil. Journal of Spectroscopy. 2013; 2013.

13. Swann GE, Patwardhan S. Application of Fourier Transform Infrared Spectroscopy (FTIR) for assessing biogenic silica sample purity in geochemical analyses and palaeoenvironmental research. Climate of the Past. 2011; 7: 65-74.

14. Gallignani M, Rondon RA, Ovalles JF, Brunetto MR. Transmission FTIR derivative spectroscopy for estimation of furosemide in raw material and tablet dosage form. Acta Pharmaceutica Sinica B. 2014; 4: 376-383.

15. Camlibel NO, Arik B. Sol-gel applications in textile finishing processes. Recent applications in sol-gel synthesis Intech Open Limited, UK. 2017: 253-281.

16. Pereira E, Silva IdS, Gomide RG, PIRES MA. Analytical method development and validation for quantification of uranium by Fourier Transform Infrared Spectroscopy (FTIR) for routine quality control analysis. 2015.

17. Chen Y, Zou C, Mastalerz M, Hu S, Gasaway C, Tao X. Applications of microFourier Transform Infrared Spectroscopy (FTIR) in the geological sciences-a review. International journal of molecular sciences. 2015; 16: 30223-30250.

18. Lopes J, Correia M, Martins I, Henriques AG, Delgadillo I, da Cruz e Silva O, et al. FTIR and Raman spectroscopy applied to dementia diagnosis through analysis of biological fluids. Journal of Alzheimer's Disease. 2016; 52: 801812.

19. Doyle WM. Principles and applications of Fourier Transform Infrared (FTIR) process analysis. Process Control Qual. 1992; 2: 11-41.

20. Kumar Y, Karne SC. Spectral analysis: A rapid tool for species detection in meat products. Trends in food science \& technology. 2017; 62: 59-67.

21. Chan KA, Kazarian SG. Attenuated Total Reflection Fourier-Transform Infrared (ATR-FTIR) imaging of tissues and live cells. Chemical Society Reviews. 2016; 45: 1850-1864.

22. von Aulock FW, Kennedy BM, Schipper Cl, Castro J, Martin D, Oze C, et al. Advances in Fourier transform infrared spectroscopy of natural glasses: From sample preparation to data analysis. Lithos. 2014; 206: 52-64.

23. Tatulian SA. FTIR analysis of proteins and protein-membrane interactions. Lipid-Protein Interactions: Springer. 2019: 281-325.

24. Faghihzadeh F, Anaya NM, Schifman LA, Oyanedel-Craver V. Fourier transform infrared spectroscopy to assess molecular-level changes in microorganisms exposed to nanoparticles. Nanotechnology for Environmental Engineering. 2016; 1: 1

25. Smith BC. Infrared spectral interpretation: a systematic approach. CRC press. 1998.

26. Pavia DL, Lampman GM, Kriz GS, Vyvyan JA. Introduction to spectroscopy. Cengage Learning. 2008.

27. Dutta A. Fourier transform infrared spectroscopy. Spectroscopic methods for 
nanomaterials characterization. Elsevier. 2017: 73-93.

28. Bokhart MT, Manni J, Garrard KP, Ekelof M, Nazari M, Muddiman DC. IRMALDESI Mass Spectrometry Imaging at 50 Micron Spatial Resolution. Journal of the American Society for Mass Spectrometry. 2017; 28: 20992107.

29. Fakayode SO, Baker GA, Bwambok DK, Bhawawet N, Elzey B, Siraj N, et al Molecular (Raman, NIR, and FTIR) spectroscopy and multivariate analysis in consumable products analysis1. Applied Spectroscopy Reviews. 2019: 1-77.

30. Ostrander JS, Serrano AL, Ghosh A, Zanni MT. Spatially Resolved Two Dimensional Infrared Spectroscopy via Wide-Field Microscopy. ACS photonics. 2016; 3: 1315-1323.

31. Morhart TA, Quirk A, Lardner MJ, May TE, Rosendahl SM, Burgess IJ. Femtomole Infrared Spectroscopy at the Electrified Metal-Solution Interface. Analytical chemistry. 2016; 88: 9351-9354

32. Wei S, Kulkarni P, Ashley K, Zheng L. Measurement of Crystalline Silica Aerosol Using Quantum Cascade Laser-Based Infrared Spectroscopy. Scientific reports. 2017; $7: 13860$.

33. Fanelli S, Zimmermann A, Totoli EG, Salgado HRN. FTIR Spectrophotometry as a Green Tool for Quantitative Analysis of Drugs: Practical Application to Amoxicillin. Journal of Chemistry. 2018; 2018: 1-8.

34. Siregar C, Martono S, Rohman A. Application of Fourier Transform Infrared (FTIR) spectroscopy coupled with multivariate calibration for quantitative analysis of curcuminoid in tablet dosage form. J Appl Pharm. 2018; 8: 151156

35. Patel A, Panchal A, Patel V, Nagar A. FTIR Spectroscopic Method For Quantitative Analysis Of Cilnidipine In Tablet Dosage Form. International Journal of Pharma Sciences and Research. 2015; 6: 1033-1039.

36. Mallah MA, Sherazi ST, Bhanger MI, Mahesar SA, Bajeer MA. A rapid FourierTransform Infrared (FTIR) spectroscopic method for direct quantification of paracetamol content in solid pharmaceutical formulations. Spectrochimica acta Part A, Molecular and biomolecular spectroscopy. 2015; 141: 64-70.

37. Natori JS, Totoli EG, Salgado HR. Development and Validation of a Green Analytical Method for the Determination of Norfloxacin in Raw Material by FTIR Spectrophotometry. Journal of AOAC International. 2016; 99: 15331536.

38. Vasconcelos M, Coelho L, Barros A, de Almeida JMMM, Yildiz F. Study of adulteration of extra virgin olive oil with peanut oil using FTIR spectroscopy and chemometrics. Cogent Food \& Agriculture. 2015; 1

39. Fahmi Z, Mudasir M, Rohman A. Attenuated Total Reflectance-FTIR Spectra Combined with Multivariate Calibration and Discrimination Analysis for Analysis of Patchouli Oil Adulteration. Indonesian Journal of Chemistry. 2020; 20: 1.

40. Jiménez-Carvelo AM, Osorio MT, Koidis A, González-Casado A, CuadrosRodríguez L. Chemometric classification and quantification of olive oil in blends with any edible vegetable oils using FTIR-ATR and Raman spectroscopy. Lwt. 2017; 86: 174-184

41. Kou Y, Li Q, Liu X, Zhang R, Yu X. Efficient Detection of Edible Oils Adulterated with Used Frying Oils through PE-film-based FTIR Spectroscopy Combined with DA and PLS. Journal of oleo science. 2018; 67: 1083-1089.

42. Arslan FN, Çağlar F. Attenuated Total Reflectance-Fourier Transform Infrared (ATR-FTIR) Spectroscopy Combined with Chemometrics for Rapid Determination of Cold-Pressed Wheat Germ Oil Adulteration. Food Analytical Methods. 2018; 12: 355-370.

43. Terouzi W, Omari S, Boutoial K, Oussama A. Quantitative detection of cow milk in goat milk by chemometrics analysis based on mid infrared spectroscopy. Quest Journals Journal of Research in Agriculture and Animal Science. 2016; 4: 1-7.

44. Souhassou S, Bassbasi M, Hirri A, Kzaiber F, Oussama A. Detection of camel milk adulteration using Fourier transformed infrared spectroscopy FT-IR coupled with chemometrics methods. International Food Research Journal. 2018; 25: 1213-1218
45. Mabood F, Hussain J, Al Nabhani M, Gilani S. Detection and quantification of formalin adulteration in cow milk using near infrared spectroscopy combined with multivariate analysis. J Adv Dairy Res. 2017; 5.

46. Wu T, Chen H, Lin Z, Tan C. Identification and quantitation of melamine in milk by near-infrared spectroscopy and chemometrics. Journal of Spectroscopy. 2016; 2016.

47. Casarrubias-Torres LM, Meza-Márquez OG, Osorio-Revilla G, GallardoVelazquez T. Mid-infrared spectroscopy and multivariate analysis for determination of tetracycline residues in cow's milk. Acta Veterinaria Brno. 2018; 87: 181-188.

48. Weldegebreal B, Redi-Abshiro M, Chandravanshi BS. Development of new analytical methods for the determination of caffeine content in aqueous solution of green coffee beans. Chemistry Central Journal. 2017; 11: 126.

49. Reis N, Franca AS, Oliveira LS. Concomitant use of Fourier transform infrared attenuated total reflectance spectroscopy and chemometrics for quantification of multiple adulterants in roasted and ground coffee. Journal of Spectroscopy. 2016; 2016.

50. Terouzi W, Oussama A. Mid-infrared spectroscopy and chemometric tools applied to quantification of adulteration in Arabica coffee by addition of roasted barley. 2016; 3 .

51. Craig AP, Franca AS, Oliveira LS, Irudayaraj J, Ileleji K. Fourier transform infrared spectroscopy and near infrared spectroscopy for the quantification of defects in roasted coffees. Talanta. 2015; 134: 379-386

52. Guntarti A. FTIR Spectroscopy in Combination with Chemometrics for Analysis of Wild Boar Meat in Meatball Formulation. Asian Journal of Biochemistry. 2015; 10: 165-172.

53. Rahmania H, Rohman A. The employment of FTIR spectroscopy in combination with chemometrics for analysis of rat meat in meatball formulation. Meat science. 2015; 100: 301-305

54. Pebriana RB, Rohman A, Lukitaningsih E, Sudjadi. Development of FTIR spectroscopy in combination with chemometrics for analysis of rat meat in beef sausage employing three lipid extraction systems. International journal of food properties. 2017; 20: 1995-2005.

55. Rahayu WS, Rohman A, Martono S, Sudjadi S. Application of FTIR Spectroscopy and Chemometrics for Halal Authentication of Beef Meatball Adulterated with Dog Meat. Indonesian Journal of Chemistry. 2018; 18: 376381.

56. Keshavarzi Z, Banadkoki SB, Faizi M, Zolghadri Y, Shirazi FH. Comparison of transmission FTIR and ATR spectra for discrimination between beef and chicken meat and quantification of chicken in beef meat mixture using ATRFTIR combined with chemometrics. Journal of Food Science and Technology. 2019; 57: 1430-1438.

57. Eliaerts J, Dardenne P, Meert N, Van Durme F, Samyn N, Janssens K, et al. Rapid classification and quantification of cocaine in seized powders with ATR-FTIR and chemometrics. Drug testing and analysis. 2017; 9: 1480-1489.

58. Grobério TS, Zacca JJ, Talhavini M, Braga JW. Quantification of cocaine hydrochloride in seized drug samples by infrared spectroscopy and PLSR. Journal of the Brazilian Chemical Society. 2014; 25: 1696-1703.

59. Grobério TS, Zacca JJ, Botelho ÉD, Talhavini M, Braga JW. Discrimination and quantification of cocaine and adulterants in seized drug samples by infrared spectroscopy and PLSR. Forensic science international. 2015; 257: 297-306.

60. Pérez-Alfonso C, Galipienso N, Garrigues S, de la Guardia M. Preliminary results on direct quantitative determination of cocaine in impregnated materials by infrared spectroscopy. Microchemical Journal. 2018; 143: 110117.

61. Shapaval V, Brandenburg J, Blomqvist J, Tafintseva V, Passoth V, Sandgren $\mathrm{M}$, et al. Biochemical profiling, prediction of total lipid content and fatty acid profile in oleaginous yeasts by FTIR spectroscopy. Biotechnology for biofuels. 2019; $12: 140$.

62. Tarhan I, Ismail AA, Kara H. Quantitative determination of free fatty acids in extra virgin olive oils by multivariate methods and Fourier transform infrared 
spectroscopy considering different absorption modes. International journal of food properties. 2017; 20: S790-S797.

63. Mazurek S, Szostak R, Kita A. Application of infrared reflection and Raman spectroscopy for quantitative determination of fat in potato chips. Journal of Molecular Structure. 2016; 1126: 213-218.

64. Olale K, Walyambillah W, Mohammed SA, Sila A, Shepherd K. Application of DRIFT-FTIR spectroscopy for quantitative prediction of simple sugars in two local and two Floridian mango (Mangifera indica L.) cultivars in Kenya. Journal of Analytical Science and Technology. 2017; 8: 21.

65. Nair R, Venkatesh S, Athmaselvi K, Thakur S. Rapid estimation and quantification of sucrose content in fruit juices using Fourier Transform Infrared-Attenuated Total Reflectance (FTIR-ATR) spectroscopy. Journal of Food Measurement and Characterization. 2016; 10: 24-31.

66. Wang Y-T, Li B, Xu X-J, Ren H-B, Yin J-Y, Zhu H, et al. FTIR spectroscopy coupled with machine learning approaches as a rapid tool for identification and quantification of artificial sweeteners. Food chemistry. 2020; 303: 125404.

67. Chen J, Sun S, Zhou Q. Rapid identification and quantification of carbohydrate excipients in Gardeniae Fructus formula granules by ATR-FTIR spectroscopy. Analytical Methods. 2016; 8: 8329-8336.

68. Hou S-W, Wei W, Wang Y, Gan J-H, Lu Y, Tao N-P, et al. Integrated recognition and quantitative detection of starch in surimi by infrared spectroscopy and spectroscopic imaging. Spectrochimica Acta Part A: Molecular and Biomolecular Spectroscopy. 2019; 215: 1-8.

69. Tiwari S, Deb MK, Sen BK. Cloud point extraction and diffuse reflectanceFourier transform infrared spectroscopic determination of chromium (VI): A probe to adulteration in food stuffs. Food chemistry. 2017; 221: 47-53.

70. Lohumi S, Joshi R, Kandpal LM, Lee H, Kim MS, Cho H, et al. Quantitative analysis of Sudan dye adulteration in paprika powder using FTIR spectroscopy. Food Additives \& Contaminants: Part A. 2017; 34: 678-686.

71. Erwanto Y, Muttaqien AT, Sugiyono, Sismindari, Rohman A. Use of Fourier transform infrared (FTIR) spectroscopy and chemometrics for analysis of lard adulteration in "rambak" crackers. International Journal of Food Properties. 2016; 19: 2718-2725.
72. Se KW, Ghoshal SK, Wahab RA, Ibrahim RKR, Lani MN. A simple approach for rapid detection and quantification of adulterants in stingless bees (Heterotrigona itama) honey. Food Research International. 2018; 105: 453460.

73. Valderrama ACS, De GCR. Traceability of active compounds of essential oils in antimicrobial food packaging using a chemometric method by ATR-FTIR American Journal of Analytical Chemistry. 2017; 8: 726.

74. Wang K, Yuan Y, Han S, Yang Y. Application of FTIR spectroscopy with solvent-cast film and PLS regression for the quantification of SBS content in modified asphalt. International Journal of Pavement Engineering. 2019; 20: 1336-1341

75. Kurrey R, Mahilang M, Deb MK, Nirmalkar J, Shrivas K, Pervez S, et al. A direct DRS-FTIR probe for rapid detection and quantification of fluoroquinolone antibiotics in poultry egg-yolk. Food chemistry. 2019; 270: 459-466.

76. Dadson J, Pandam S, Asiedu N. Modeling the characteristics and quantification of adulterants in gasoline using FTIR spectroscopy and chemometric calibrations. Cogent Chemistry. 2018; 4: 1482637.

77. Feist PL. Sampling technique for organic solids in ir spectroscopy: thin solid films as the method of choice in teaching laboratories. Journal of Chemical Education. 2001; 78: 351.

78. Mohamed MA, Jaafar J, Ismail A, Othman M, Rahman M. Fourier transform infrared (FTIR) spectroscopy. Membrane Characterization: Elsevier. 2017: 3-29.

79. Andrei AB, Fleschin S, Aboul-Enein HY. Cancer diagnosis by FT-IR Spectrophotometry. Rev Roum Chim. 2015; 60: 415-426.

80. Bageshwar DV, Pawar AS, Khanvilkar VV, Kadam VJ. Photoacoustic spectroscopy and its applications: A tutorial review. Eurasian Journal of Analytical Chemistry. 2010; 5: 187-203. 